Article

\title{
Fucoxanthin Holds Potential to Become a Drug Adjuvant in Breast Cancer Treatment: Evidence from 2D and 3D Cell Cultures
}

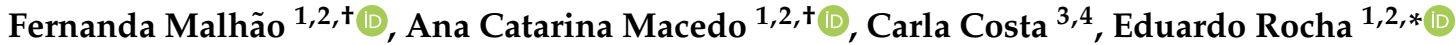 \\ and Alice Abreu Ramos 1,2
}

1 Institute of Biomedical Sciences Abel Salazar (ICBAS), University of Porto (U.Porto), Rua de Jorge Viterbo Ferreira 228, 4050-313 Porto, Portugal; fcmalhao@icbas.up.pt (F.M.); acfpmacedo@gmail.com (A.C.M.); ramosalic@gmail.com (A.A.R.)

2 Interdisciplinary Center for Marine and Environmental Research (CIIMAR), University of Porto (U.Porto), Avenida General Norton de Matos, 4450-208 Matosinhos, Portugal

3 Environmental Health Department, National Health Institute Dr. Ricardo Jorge, Rua Alexandre Herculano 321, 4000-055 Porto, Portugal; carla.trindade@insa.min-saude.pt

4 EPIUnit-Instituto de Saúde Pública, University of Porto (U.Porto), Rua das Taipas 135, 4050-600 Porto, Portugal

* Correspondence: erocha@icbas.up.pt

+ Fernanda Malhão and Ana Catarina Macedo contributed equally to this work and are joint first authors.

check for updates

Citation: Malhão, F.; Macedo, A.C.; Costa, C.; Rocha, E.; Ramos, A.A. Fucoxanthin Holds Potential to Become a Drug Adjuvant in Breast Cancer Treatment: Evidence from 2D and 3D Cell Cultures. Molecules 2021, 26, 4288. https://doi.org/10.3390/ molecules26144288

Academic Editors: Madalena Pinto and Marta Correia-da-Silva

Received: 14 June 2021

Accepted: 11 July 2021

Published: 15 July 2021

Publisher's Note: MDPI stays neutral with regard to jurisdictional claims in published maps and institutional affiliations.

Copyright: (c) 2021 by the authors. Licensee MDPI, Basel, Switzerland. This article is an open access article distributed under the terms and conditions of the Creative Commons Attribution (CC BY) license (https:/ / creativecommons.org/licenses/by/ $4.0 /)$.

\begin{abstract}
Fucoxanthin (Fx) is a carotenoid derived from marine organisms that exhibits anticancer activities. However, its role as a potential drug adjuvant in breast cancer (BC) treatment is still poorly explored. Firstly, this study investigated the cytotoxic effects of Fx alone and combined with doxorubicin (Dox) and cisplatin (Cis) on a panel of 2D-cultured BC cell lines (MCF7, SKBR3 and MDA-MB-231) and one non-tumoral cell line (MCF12A). Fucoxanthin induced cytotoxicity against all the cell lines and potentiated Dox cytotoxic effects towards the SKBR3 and MDA-MB-231 cells. The combination triggering the highest cytotoxicity (Fx $10 \mu \mathrm{M}+$ Dox $1 \mu \mathrm{M}$ in MDA-MB-231) additionally showed significant induction of cell death and genotoxic effects, relative to control. In sequence, the same combination was tested on 3D cultures using a multi-endpoint approach involving bioactivity assays and microscopy techniques. Similar to 2D cultures, the combination of Fx and Dox showed higher cytotoxic effects on 3D cultures compared to the isolated compounds. Furthermore, this combination increased the number of apoptotic cells, decreased cell proliferation, and caused structural and ultrastructural damages on the 3D models. Overall, our findings suggest Fx has potential to become an adjuvant for Dox chemotherapy regimens in BC treatment.
\end{abstract}

Keywords: cisplatin; combinatorial therapy; doxorubicin; fucoxanthin; seaweed compounds; triple-negative breast cancer

\section{Introduction}

Nature has always been a source of active substances for drug development, and despite the advances in synthetic biology, most of the currently approved medicines are based on natural products [1,2]. In fact, more than $60 \%$ of the anticancer drugs used in clinical practice are derived from natural sources, including the well-known chemotherapeutics doxorubicin (Dox), paclitaxel, vincristine and vinblastine [1,3]. In the last few decades, there has been a growing interest in exploring the marine ecosystem for drug discoveries [4,5]. Marine organisms yield a wide variety of bioactive compounds with unique properties and promising potential for developing new anticancer drugs [6,7]. Recent data report that, so far, five marine-derived drugs have been approved for cancer treatment [8], while 24 drug candidates are being tested in clinical trials [9]. 
Among marine organisms, seaweeds (or macroalgae) bear a high content of phytochemicals (e.g., carotenoids, polyphenolic compounds and polysaccharides) with promising chemopreventive and chemotherapeutic properties towards several types of cancer, namely breast cancer (BC) [10]. Interestingly, in Asiatic folk medicine, seaweeds have been used since ancient times as potential weapons to treat BC [11]. Besides, some studies have also been pointing out the benefits of dietary seaweed consumption on the prevention of $\mathrm{BC}[12,13]$.

Fucoxanthin (Fx) is one of the most abundant xanthophyll carotenoids of the marine environment that is mainly found in brown seaweeds such as the popular edible algae Wakame (Undaria pinnatifida) [14,15]. This orange-colored pigment is known for having distinct health-promoting activities, such as anti-inflammatory, antioxidant, antidiabetic, anti-obesity and anticancer effects in various types of cancers [16-22], including BC [23]. The anticancer effects comprise proapoptotic, antiproliferative, antimetastatic and antiangiogenic activities [24]. In BC cells, Fx increases apoptosis [14,22,23] and decreases lymphangiogenesis [25].

$\mathrm{BC}$ is currently the most prevalent cancer and the leading cause of cancer-related deaths amongst females worldwide [26,27]. In 2020, there were 2.3 million women diagnosed with this disease, accounting for 685,000 deaths globally [28]. BC comprises tumors with high heterogeneity and a wide variety of histological and molecular features, which translate into distinct biological behaviors and treatments [29]. According to the St. Gallen International Breast Cancer Conference 2013, BC is classified into four molecular subtypes: Luminal A, Luminal B, HER-2 overexpression, and triple-negative. These BC subtypes are differentiated by the presence of estrogen receptor (ER), progesterone receptor (PgR) and different expression levels of the human epidermal growth factor receptor 2 (HER-2) and antigen Ki67 [30]. Luminal A (ER+/PgR+/HER-2- with low ki67) and B (ER+/PgR+/HER-2- with high ki67) subtypes present the lowest recurrence rates and the best prognosis [30,31], being typically treated with hormonal therapy or a combination of both chemotherapy and hormonal treatments [32]. The HER-2 overexpression subtype (ER-/PR-/HER-2+) is linked with an aggressive phenotype and worse prognosis, however, it is often successfully treated with HER-2 targeted therapies, such as trastuzumab and pertuzumab [33]. The triple-negative BC (TNBC) subtype (ER-/PR-/HER-2-) accounts for the poorest clinical outcomes due to its aggressive metastatic behavior and the lack of targeted therapies, being chemotherapy the single treatment option currently available [34]. Despite being the most chemotherapy-responsive subtype, TNBCs still present the highest recurrence and metastasis rate compared to other BCs [35].

Current neoadjuvant or adjuvant chemotherapy treatments for BC usually involve the administration of reference anticancer drugs such as Dox, cisplatin (Cis), or paclitaxel isolated or in combination regimens [36]. While commonly used, chemotherapy drugs can cause severe adverse effects, as they induce cytotoxicity in non-target cells (non-tumorigenic cells) [37]. For instance, Dox is normally associated with cardiotoxicity, myelosuppression, intestinal epithelium lesions [36], and Cis can induce nephrotoxicity, neurotoxicity and hearing impairments [38]. Additionally, the onset of multidrug resistance is still one of the major hurdles of chemotherapy, being responsible for the death of many cancer patients [37]. Therefore, strategies to overcome chemotherapy-associated limitations are in need, encouraging the search for new anticancer drugs or adjuvant drugs.

In this vein, recent reports have shown that the combination of established anticancer drugs with natural products, such as marine-derived compounds, can potentiate drug efficacy and reduce the administered doses, causing the mitigation of the associated adverse effects and preventing the onset of drug resistance [39,40].

Although data are scarce, a few studies tested the effects of Fx in combination with conventional anticancer drugs such as 5-Fluorouracil [41], Imatinib [42] and Dox [43]. A recent review on the mechanisms of the anticancer effects of Fx and its combination with chemotherapy drugs reported that generally the combinations were more effective than either Fx or the drugs alone [44]. However, more mechanistic studies are required to investigate the interactions of Fx with anticancer drugs and elucidate the processes 
underlying the combinatorial effects. Knowledge on this subject is of utmost importance not only for oncological medicine, but also for the field of nutritional therapy, as seaweeds can be included in diets or be consumed as dietary supplements [45].

Most of the existing data regarding the anticancer effects of Fx were obtained from in vitro studies using monolayer cultures. Despite providing valuable information in the scope of oncology drug discovery, 2D cell culture models present several limitations in predicting drug activity and toxicity in vivo [46,47]. One of the main disadvantages of these models is the lack of interactions between cell-cell and cell-extracellular environment. These are usually found in solid tumors, affecting cell polarity and other related cellular functions, including proliferation and differentiation, viability, apoptosis, proteins and gene expression, response to stimuli, and drug metabolism [48]. Accumulating evidence confirms that cells grown in a 3D physical shape have a better predictive capacity of in vivo cellular responses than cells grown as a monolayer [49,50].

To make up for the current lack of information, this study aimed to: (1) evaluate the cytotoxic effects of Fx alone and in combination with reference drugs-Cis or Dox-on a panel of four 2D-cultured cell lines (three BC cell lines of different molecular subtypes and one non-tumoral breast cell line); (2) select the combination with the most promising cytotoxic effect and further investigate its effects in the respective 3D cell model; and (3) explore some possible underlying anticancer mechanisms of that combination on both cell models, using bioactivity assays and microscopy techniques.

\section{Results}

\subsection{Phase 1-Cytotoxic Effects of Fx Alone in 2D Cell Cultures}

The cytotoxicity of Fx was evaluated by the MTT assay after $72 \mathrm{~h}$ of exposure. Fucoxanthin induced dose-dependent cytotoxic effects in all the tested cell lines at concentrations equal to or above $10 \mu \mathrm{M}$ (Figure 1). At 10 and $20 \mu \mathrm{M}$, Fx reduced the viability of MCF7, SKBR3 and MDA-MB-231 cells to approximately 62 and 22\%, respectively. For the MCF12A cells treated with the same concentrations, the viability decreased to around 74 and $31 \%$. At the highest tested concentration $(50 \mu \mathrm{M})$, Fx induced significant cytotoxic effects on all the cell lines by reducing their viabilities to nearly $10 \%$.

(a) MCF7

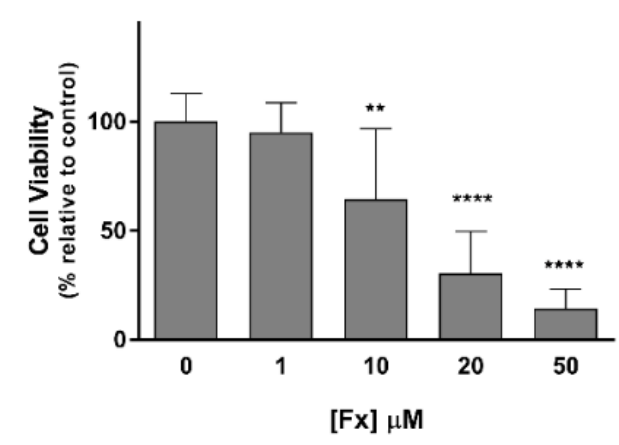

(b) SKBR3

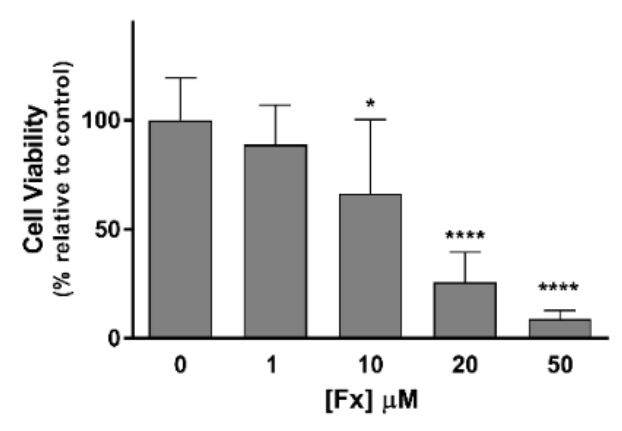

Figure 1. Conts. 
(c) MDA-MB-231

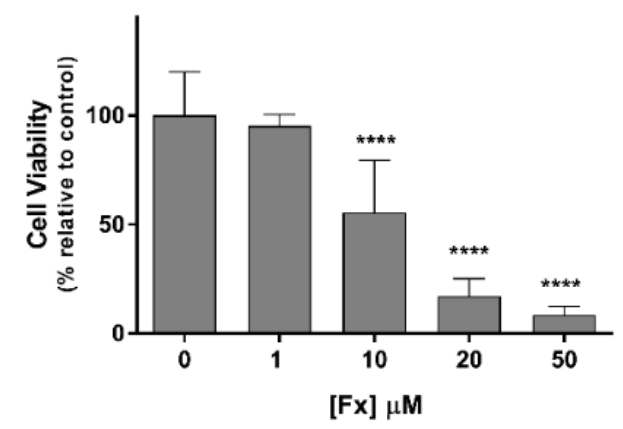

(d) MCF12A

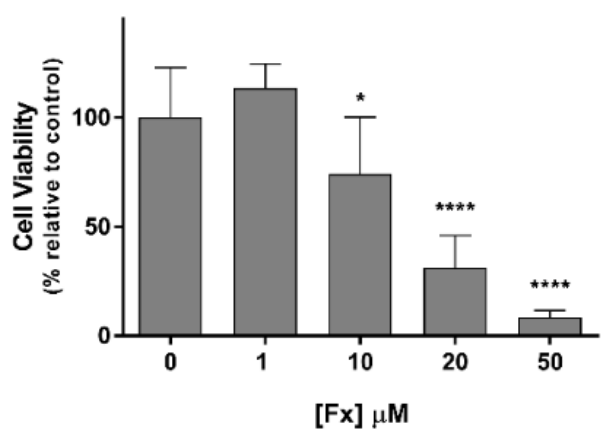

Figure 1. Effects of Fx on the viability of MCF7 (a), SKBR3 (b), MDA-MB-231 (c) and MCF12A (d) cells, assessed by the MTT assay after $72 \mathrm{~h}$ of incubation. Results are expressed as mean + standard deviation of six independent experiments. Asterisks indicate significant differences relative to control $\left({ }^{*} p<0.05 ;{ }^{* *} p<0.01 ;{ }^{* * *} p<0.0001\right)$.

\subsection{Phase 2-Cytotoxic Effects of Fx Combined with Dox or Cis in 2D Cell Cultures}

Considering the cytotoxicity data and the selection criteria defined in Section 4.4, two concentrations of Fx and two concentrations of Dox and Cis were selected to be tested in combination on the panel of $\mathrm{BC}$ cell lines. The effects of these mixtures and respective isolated compounds on cell viability were determined by the MTT assay after $72 \mathrm{~h}$.

Regarding the MCF7 and SKBR3 cells (Figure 2a,b), the drug Cis at 10 and $20 \mu \mathrm{M}$ markedly reduced the viability of both cell lines by $35 \%$ and $62 \%$, respectively. Additionally, all the combinations between this drug and Fx induced significant cytotoxic effects on both cell lines in relation to the control group. Still, those effects did not differ from the ones of the single compounds. Fx at $10 \mu \mathrm{M}$ induced a significant cytotoxic effect on the SKBR3 cell line, either alone or in combination with Dox at $0.1 \mu \mathrm{M}$, resulting in a reduction in cell viability of roughly $31 \%$ and $43 \%$, compared to the control. Beyond that, the mentioned combination was also found to cause significantly higher cytotoxicity than the compounds alone, resulting in a cell viability loss of $12 \%$ in relation to Fx and $18 \%$ compared to Dox.

Results from the MDA-MB-231 cell line (Figure 2c) showed that Cis alone did not induce statistically significant cytotoxic effects. However, the combination of Fx (1 or $10 \mu \mathrm{M}$ ) with Cis $20 \mu \mathrm{M}$ decreased cell viability in relation to the control. Moreover, cells treated with Dox alone at $1 \mu \mathrm{M}$ as well as with the combinations Fx $10 \mu \mathrm{M}+$ Dox $0.1 \mu \mathrm{M}$ and Fx 1/10 $\mu \mathrm{M}+$ Dox $1 \mu \mathrm{M}$ also presented a statistically significant decrease in cell viability compared to control cells. Noteworthy, the combination of Dox $1 \mu \mathrm{M}$ with Fx $10 \mu \mathrm{M}$ was the only one that remarkably decreased MDA-MB-231 viability to a percentage that statistically differed from both Fx and the drug alone. This combination was able to cause a reduction in cell viability of $73 \%$, in relation to the control, and to increase Dox cytotoxicity by approximately $26 \%$.

In line with the one-way ANOVA analysis detecting differences between groups in the MDA-MB-231 and MCF7 cell lines, the Holm-Bonferroni corrected t-tests comparing only the Fx $10 \mu \mathrm{M}$ with control ( $p<0.05$ and $p<0.001$, respectively) indicated that Fx induced statistically significant cytotoxicity in those cells.

Concerning the MCF12A cell line (Figure 2d), Fx at $10 \mu \mathrm{M}$ exhibited significant cytotoxic effects, reducing cell viability by $37 \%$ relative to the control group. Cytotoxicity was also observed in cells exposed to Cis $1 \mu \mathrm{M}$ combined with Fx $10 \mu \mathrm{M}$ and to Cis $10 \mu \mathrm{M}$, alone and combined with Fx 1 or $10 \mu \mathrm{M}$. Furthermore, Dox only significantly increased cytotoxicity in MCF12A cells when combined with Fx $1 \mu \mathrm{M}$ (Dox $0.1 \mu \mathrm{M}$ ) or Fx $10 \mu \mathrm{M}$ (Dox 0.01 and $0.1 \mu \mathrm{M})$. 
(a) MCF7

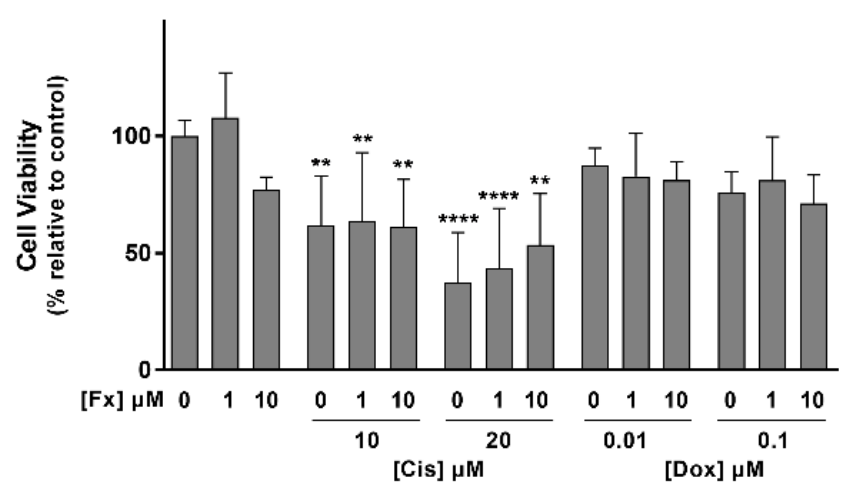

(c) MDA-MB-231

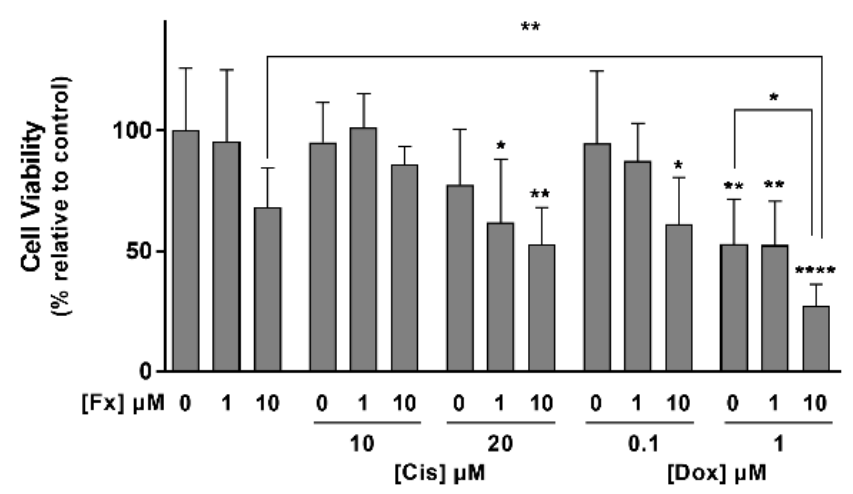

(b) SKBR3

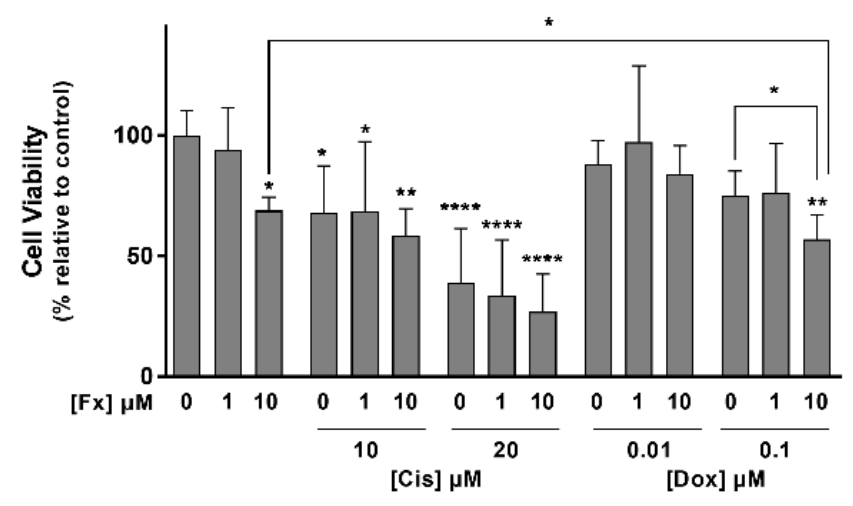

(d) MCF12A

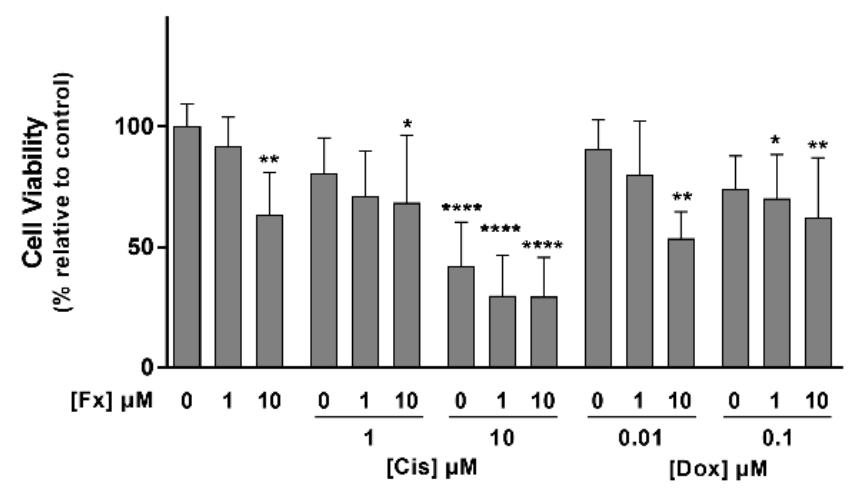

Figure 2. Effects of Fx alone and in combination with Dox or Cis on the viability of MCF7 (a), SKBR3 (b), MDA-MB-231 (c) and MCF12A (d) cells, assessed by the MTT assay after $72 \mathrm{~h}$ of incubation. Results are expressed as mean + standard deviation of five independent experiments. Asterisks indicate significant differences relative to control $\left({ }^{*} p<0.05 ;{ }^{* *} p<0.01\right.$; $\left.{ }^{* * * *} p<0.0001\right)$. Square brackets indicate differences between conditions using t-tests with sequential Holm-Bonferroni corrections.

Given all the above results, the condition Fx $10 \mu \mathrm{M}$ + Dox $1 \mu \mathrm{M}$ tested in MDA-MB-231 cells was elected as the most promising combination since it showed the highest decrease in cell viability, which statistically differed from the control and both the drug and Fx alone. To explore the possible mechanisms of action underlying its cytotoxic activity, the nuclear condensation and comet assays were performed in 2D cultures.

\subsection{Phase 3-Effects of Fx Combined with Dox on Cell Death and DNA Damage in 2D Cell Cultures}

The effect of the selected combination and respective isolated compounds on the induction of cell death in MDA-MB-231 cells was evaluated by the nuclear condensation assay after $72 \mathrm{~h}$ of exposure. Statistical results (Figure 3a) showed that Fx alone did not induce effects on cell death. On the other hand, Dox $1 \mu \mathrm{M}$ and the combination Fx $10 \mu \mathrm{M}+$ Dox $1 \mu \mathrm{M}$ markedly increased the number of cells with condensed nuclei (both around $13 \%$ ), relative to control. Concordantly, when analyzing the images from the nuclear condensation assay (Figure 3c), it was noted that those conditions exhibited a higher number of cells with condensed nuclei, as compared to Fx and the control.

Effects on DNA damage (strand breaks) were determined by the alkaline version of the comet assay following $2 \mathrm{~h}$ of exposure. According to the statistical results (Figure $3 \mathrm{~b}$ ), Dox alone and in combination with Fx showed a significant increase in DNA damages compared to the control, accounting for a tail intensity of $26 \%$ and $21 \%$, respectively. In 
both conditions, it was observed an increase of fluorescence intensity in the comet tail (Figure 3d). In contrast, both the control and Fx-treated groups presented a low level of DNA damages, as the DNA of most cells occurred as a nucleoid with no or a small tail.

(a)

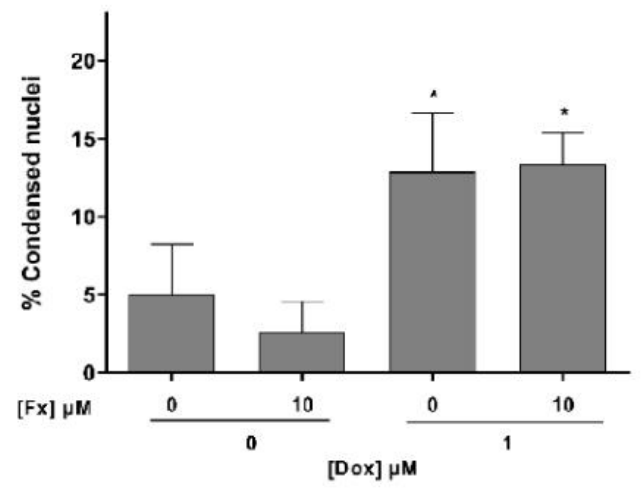

(c)

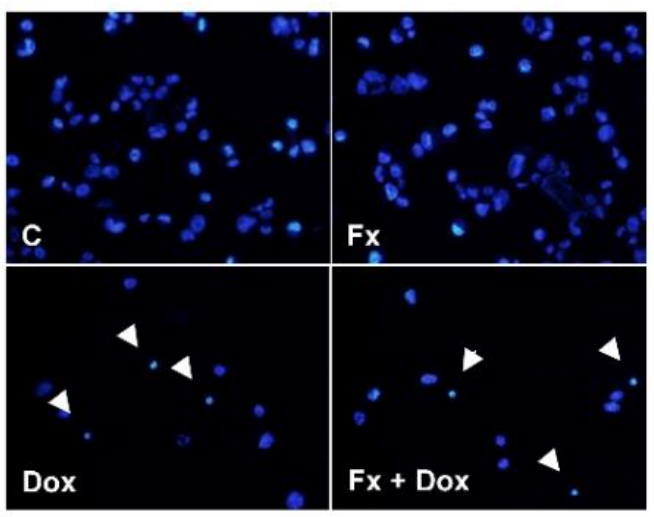

(b)

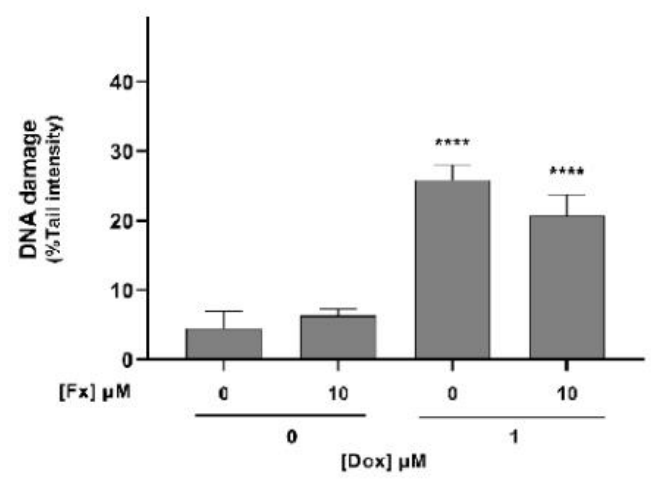

(d)

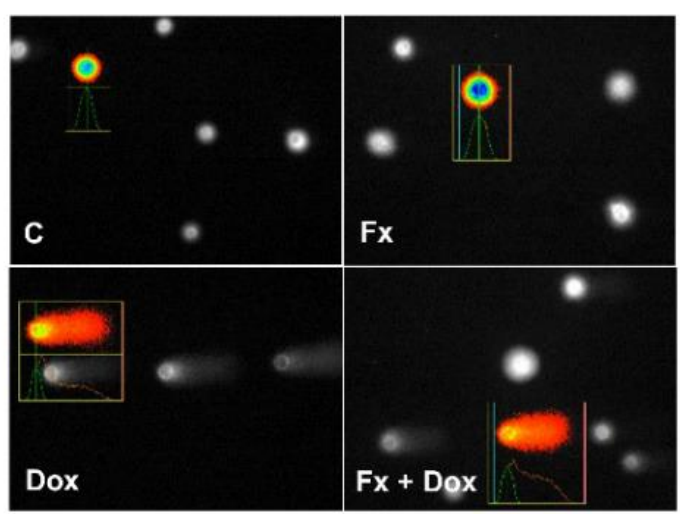

Figure 3. Effects of Fx alone and in combination with Dox on the cell death $(\mathbf{a}, \mathbf{c})$ and DNA damage (b,d) of the MDA-MB-231 cell line, assessed by the nuclear condensation and comet assays, respectively. Images illustrate the induced cell death (b) and genotoxic effects (d). The white arrowheads indicate the cells with condensed nuclei. Results are expressed as mean + standard deviation of three to five independent experiments. Asterisks indicate significant differences relative to control $(* p<0.05 ; * * * p<0.0001)$. Scale Bar: $100 \mu \mathrm{m}$.

2.4. Phase 4-Effects of Fx Combined with Dox in 3D Cell Cultures (Multicellular Aggregates-MCAs)

\subsubsection{Cytotoxic Effects}

The most promising combination in the 2D cell culture screening (Fx $10 \mu \mathrm{M}+$ Dox $1 \mu \mathrm{M})$ was selected to be tested in 3D culture. Additionally, combinations with higher concentrations of Fx $(20 \mu \mathrm{M})$ and Dox $(2 \mu \mathrm{M})$ were included, as well as a positive control for cytotoxicity (Dox $5 \mu \mathrm{M})$. Effects on cell viability were assessed by two assays: MTT and LDH.

According to the MTT assay (Figure 4a), Fx alone did not present effects on cell viability in MDA-MB-231 MCAs. Doxorubicin $(\geq 2 \mu \mathrm{M})$ and respective combinations showed cytotoxicity, with cell viabilities under $55 \%$ in relation to the control. At $1 \mu \mathrm{M}$, Dox alone did not significantly affect cell viability, but in combination with Fx $10 \mu \mathrm{M}$, it statistically differed from the control and the drug, causing a decrease in $22 \%$ of cell viability in relation to the drug and $30 \%$ in relation to the seaweed compound alone. As for the other combinations with higher Fx and Dox concentrations, they did not statistically differ from Dox alone.

In the LDH assay (Figure 4b), Fx alone did not present cytotoxic effects on the MDAMB-231 MCAs. The same was observed after exposure to Dox $1 \mu \mathrm{M}$ (alone and combined) and Dox $2 \mu \mathrm{M}$ (alone and combined with Fx $10 \mu \mathrm{M}$ ). The conditions that presented higher 
$\mathrm{LDH}$ release, differing from the control and indicating high cytotoxicity, were Dox $2 \mu \mathrm{M}$ combined with Fx $20 \mu \mathrm{M}(56 \%)$ and Dox $5 \mu \mathrm{M}(77 \%)$.

(a) MTT assay

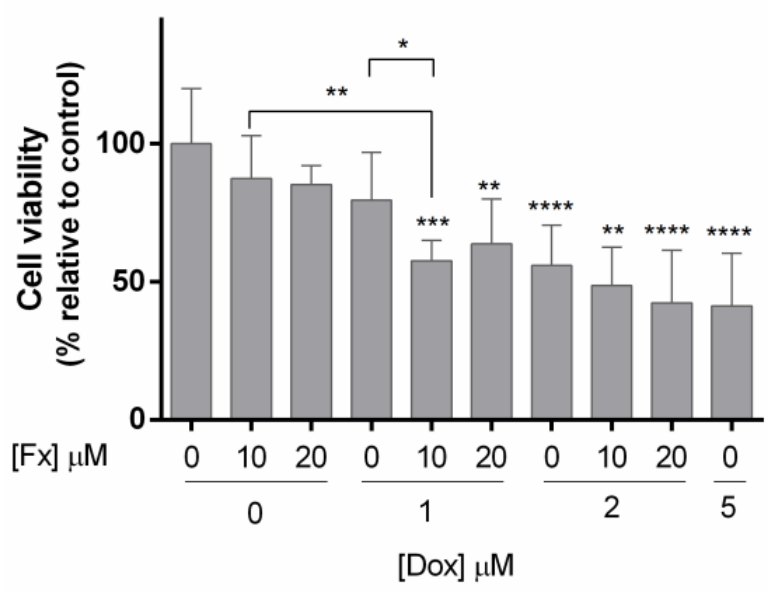

(b) LDH assay

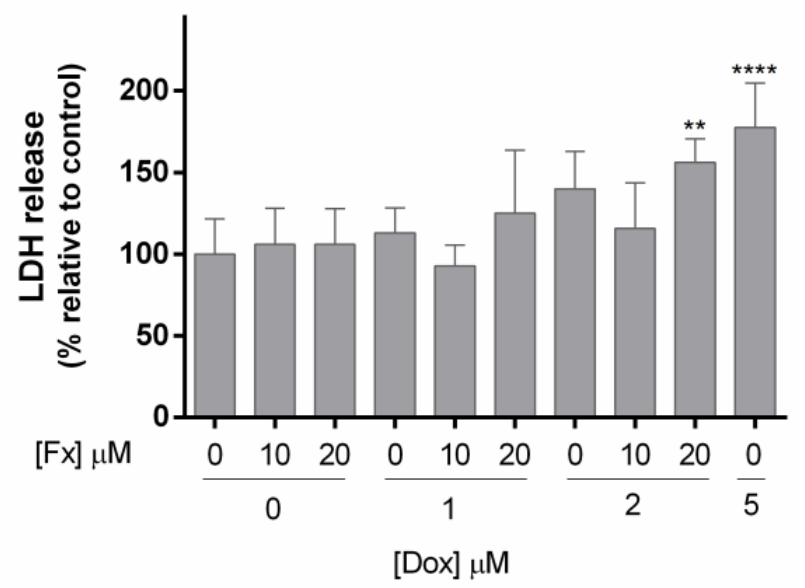

Figure 4. Effects of Fx alone and in combination with Dox on the cell viability of MDA-MB-231 MCAs, assessed by the MTT (a) and LDH (b) assays after $96 \mathrm{~h}$ of incubation. The percentages of cell viability and LDH release are relative to the control and presented as mean + standard deviation of five independent experiments (each in triplicate). Asterisks indicate significant differences relative to control $\left({ }^{*} p<0.05 ;{ }^{* *} p<0.01,{ }^{* * *} p<0.001 ;{ }^{* * *} p<0.0001\right)$. Square brackets indicate differences between conditions using $t$-tests with sequential Holm-Bonferroni corrections.

\subsubsection{Stereomicroscopic Analysis and Area Measurements}

MCAs were monitored throughout the exposure by regular observation under a stereomicroscope (Figure 5a), and photographs of each MCA were taken at the end of the exposure period $(96 \mathrm{~h})$. To explore the single and combinatory effects of Fx and Dox on the MCAs morphology, the areas of each MCA were measured by the AnaSP software. Results indicated that only the MCAs exposed to Dox $5 \mu \mathrm{M}$ presented a significant increase in area, compared to control (Figure $5 b$ ).

(a)

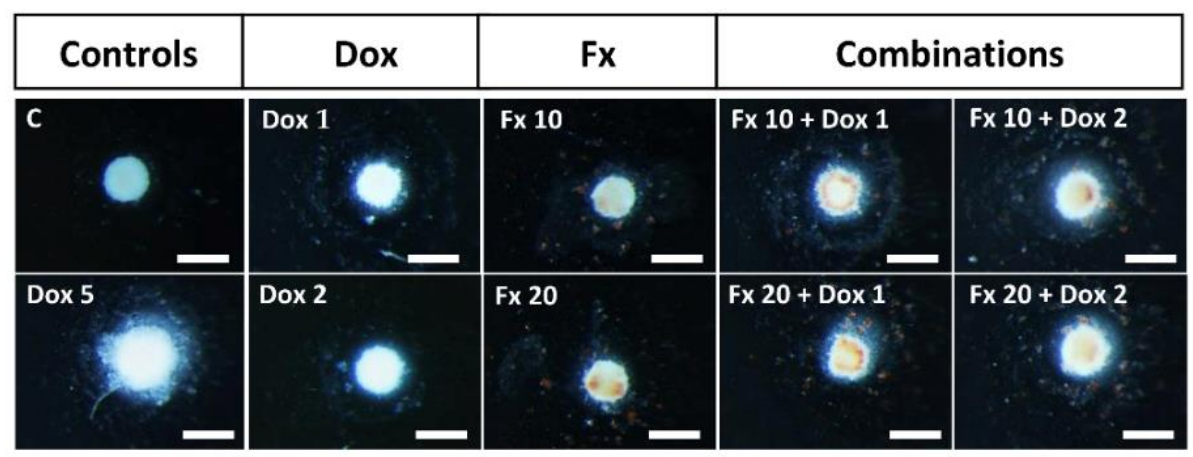

Figure 5. Conts. 
(b)

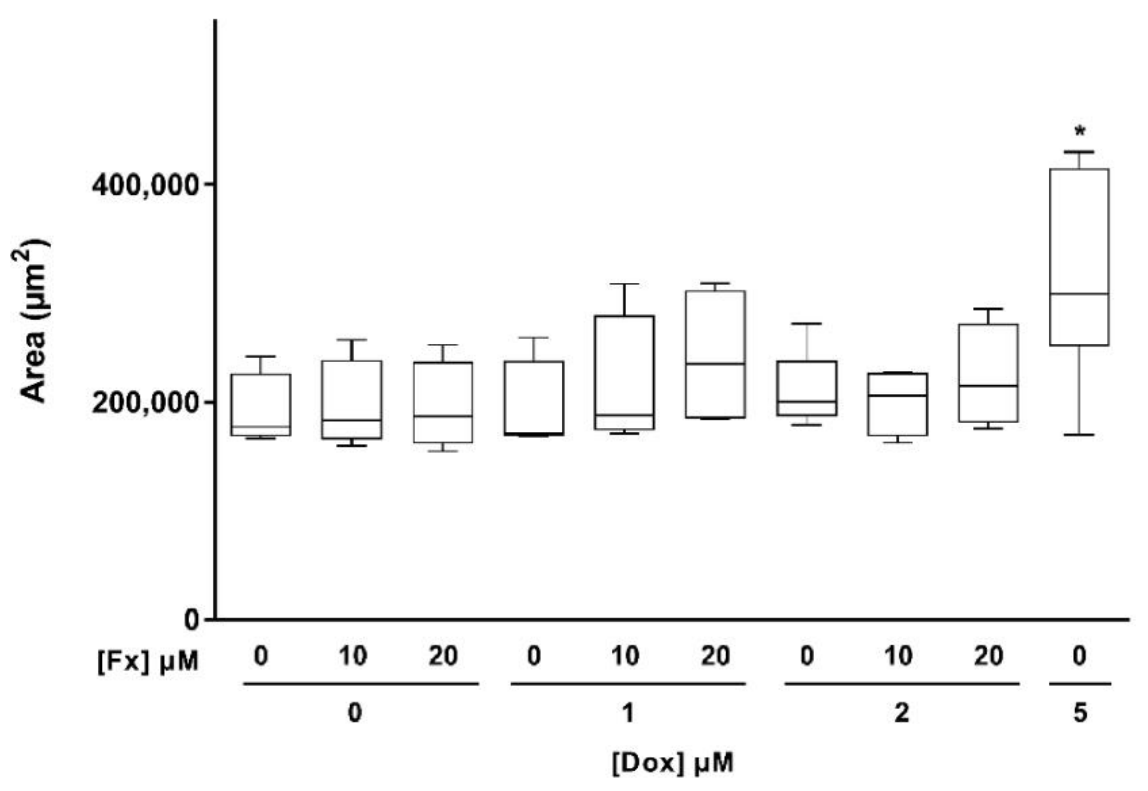

Figure 5. Representative stereomicroscopic images of MDA-MB-231 MCAs exposed to Fx (10 and $20 \mu \mathrm{M})$ and Dox $(1,2$ and $5 \mu \mathrm{M})$, alone and combined, for $96 \mathrm{~h}(\mathbf{a})$. MCAs area measurements are expressed as median, maximum, minimum and interquartile range (Q3-Q1) of four to six independent experiments (b). Asterisks indicate significant differences relative to control $\left({ }^{*} p<0.05\right)$. Scale bar: $500 \mu \mathrm{m}$.

\subsubsection{Structural and Ultrastructural Analysis}

At the end of the exposure time, MCAs from all tested conditions were fixed, and processed for light and electron microscopy. Paraffin sections were submitted to HematoxylinEosin (HE) staining for assessing the general morphology and for Immunocytochemistry (ICC) analysis to study the apoptotic and proliferative status of the MCAs. Additionally, semithin and ultrathin sections of epoxy-embedded MCAs were obtained to analyze the ultrastructural changes caused by the compounds.

\section{HE Staining}

Observation of the HE-stained MCAs (Figure 6) revealed that most MCAs presented a compact structure. This compactness was gradually lost in the exposure conditions of Dox $2 \mu \mathrm{M}>\mathrm{Fx} 20 \mu \mathrm{M}+$ Dox $2 \mu \mathrm{M}>$ Dox $5 \mu \mathrm{M}$. There was a total disaggregation of the MCAs exposed to Dox $5 \mu \mathrm{M}$ when collecting them for fixation and processing. In all MCAs, there were some cells with hyperchromatic or pyknotic nuclei; however, these features were more evident in Dox $2 \mu \mathrm{M}$ (alone and combined) and Dox $5 \mu \mathrm{M}$.

A higher degradation of the MCAs structure was noticed in the aggregates exposed to the combinations of Fx with Dox, when compared to MCAs treated with the drug alone, especially in the mixtures with Dox plus Fx $20 \mu \mathrm{M}$. These MCAs revealed an increased number of cells with an apoptotic morphology comprising pyknotic nuclei, and/or nuclear fragmentation. At the combination of Fx $20 \mu \mathrm{M}$ with Dox $1 \mu \mathrm{M}$, it was observed a marked increase in cellular eosinophilia. The same was not so evident in the combination of Fx $20 \mu \mathrm{M}$ with Dox $2 \mu \mathrm{M}$. No necrotic cores were observed in the sectioned MCAs. 


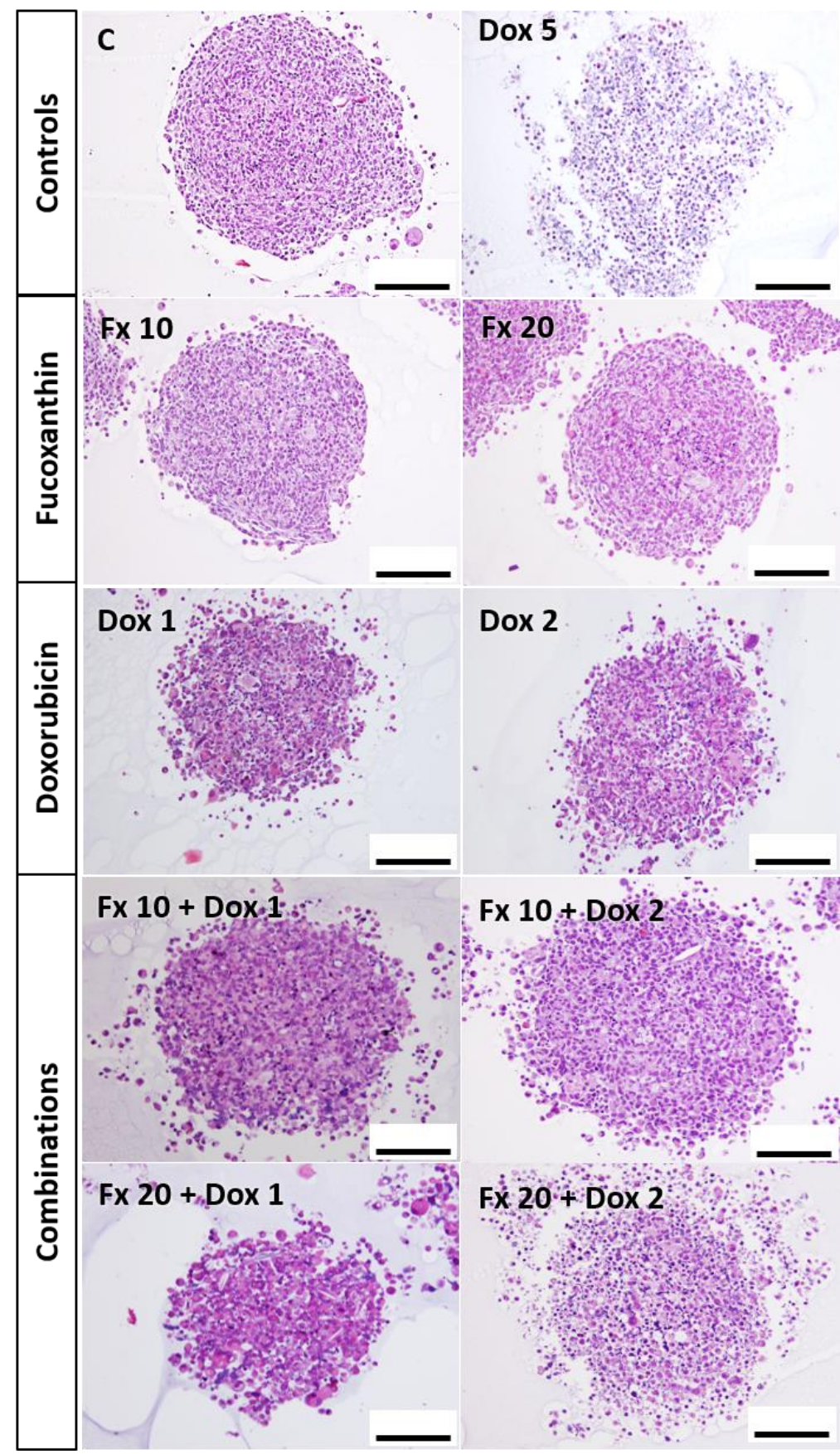

Figure 6. Representative histological images of the MDA-MB-231 MCAs exposed to Fx (10 and $20 \mu \mathrm{M})$ and Dox $(1$ and $2 \mu \mathrm{M})$, alone and combined, for $96 \mathrm{~h}$. Dox $5 \mu \mathrm{M}$ was included as a positive control. MCAs from at least three independent experiments were sectioned and stained with HE staining. Scale bar: $100 \mu \mathrm{m}$.

ICC

An ICC analysis was performed on the MCAs from all the tested conditions, and the correspondent percentages of positive cells for caspase-3 and ki67 are displayed in Figure 7. About caspase-3 (Figure 7a), the control MCAs presented, on average, 15\% of positive cells, revealed by brown staining in the cytoplasm of apoptotic cells (Figure 8). Fucoxanthin and Dox $1 \mu \mathrm{M}$ alone did not differ from the control. However, when Dox $1 \mu \mathrm{M}$ is combined with Fx 10 and $20 \mu \mathrm{M}$, statistical differences relative to control were found, presenting a significantly higher number of apoptotic cells. Additionally, Dox $2 \mu \mathrm{M}$ alone and in 
combinations with $\mathrm{Fx}$, statistically differed from the control. Still, only the combination of Fx $20 \mu \mathrm{M}+$ Dox $2 \mu \mathrm{M}$ differed from the control and both compounds alone, presenting an increase of $23 \%$ of positive cells relative to Dox $2 \mu \mathrm{M}$ alone. Figure 8 shows representative images of these conditions immunomarked with caspase-3. Most cells of the MCAs exposed to Fx $20 \mu \mathrm{M}+$ Dox $2 \mu \mathrm{M}$ are brown stained, contrasting with the control where the brown staining is restricted to a small number of cells distributed throughout the MCAs. The conditions Fx $20 \mu \mathrm{M}+$ Dox $2 \mu \mathrm{M}$ and Dox $5 \mu \mathrm{M}$ showed marked apoptotic effects as the percentages of positive cells for caspase- 3 were five times higher than the control.

Regarding the ki67 proliferation marker (Figure 7b), there was an opposite trend as the number of positive cells decreased with the compound's concentration increase. The control MCAs showed, on average, $23 \%$ of immunomarked cells, corresponding to the brown color in the nucleus (Figure 8). The ki67 positive cells were distributed in the MCAs without any preferential localization. Fx alone did not differ from the control, however, the combination of Fx $20 \mu \mathrm{M}$ with Dox $1 \mu \mathrm{M}$ showed a decrease in the number of proliferating cells ( $8.5 \%$ on average) that not only differed from the control but also from both Fx $20 \mu \mathrm{M}$ $(18 \%)$ and Dox $1 \mu \mathrm{M}(16 \%)$ alone. Representative images of ki67 immunostaining relative to this combination are given in Figure 8. Dox $2 \mu \mathrm{M}$ (alone and combined) and Dox $5 \mu \mathrm{M}$ differed from the control, showing fewer ki67-positive cells.

(a)

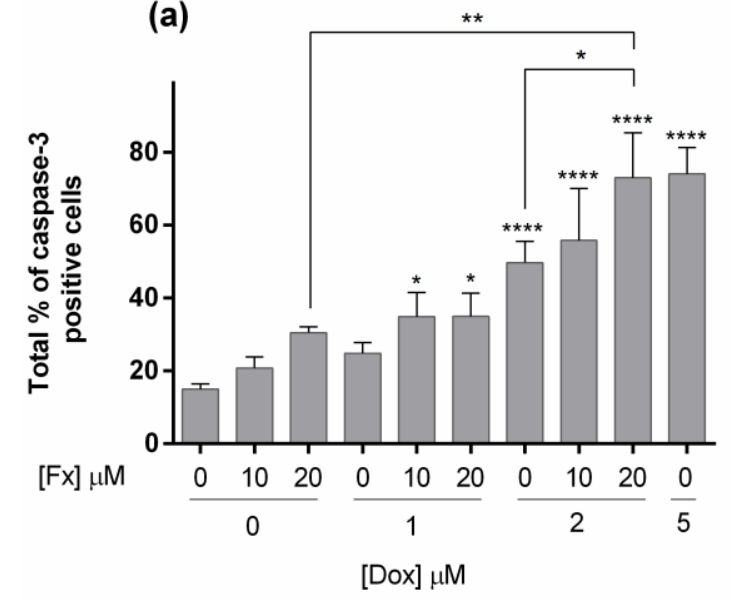

(b)

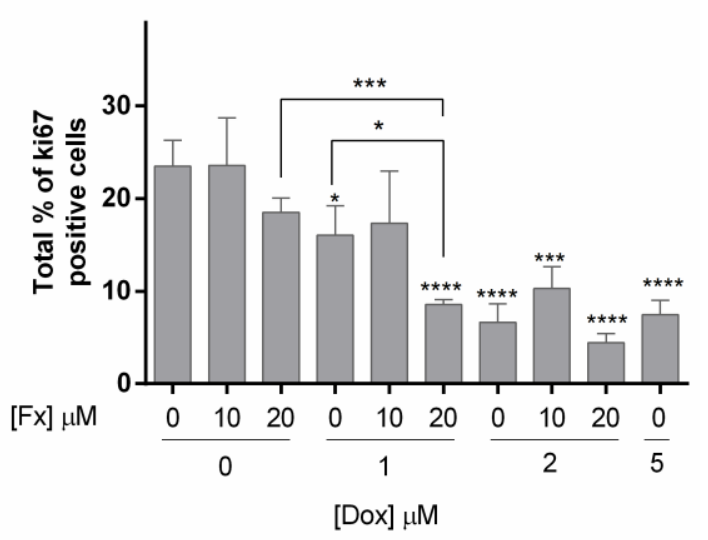

Figure 7. ICC against caspase-3 (a) and ki67 (b) in MDA-MB-231 MCAs exposed to Fx alone and in combination with Dox for $96 \mathrm{~h}$. Dox $5 \mu \mathrm{M}$ was included as a positive control. The results are expressed as absolute percentages and presented as mean + standard deviation of three independent experiments. Asterisks indicate significant differences relative to control $\left({ }^{*} p<0.05 ;{ }^{* *} p<0.01 ;{ }^{* * *} p<0.001 ;{ }^{* * *} p<0.0001\right)$. Square brackets indicate differences between conditions using t-tests with sequential Holm-Bonferroni corrections. 


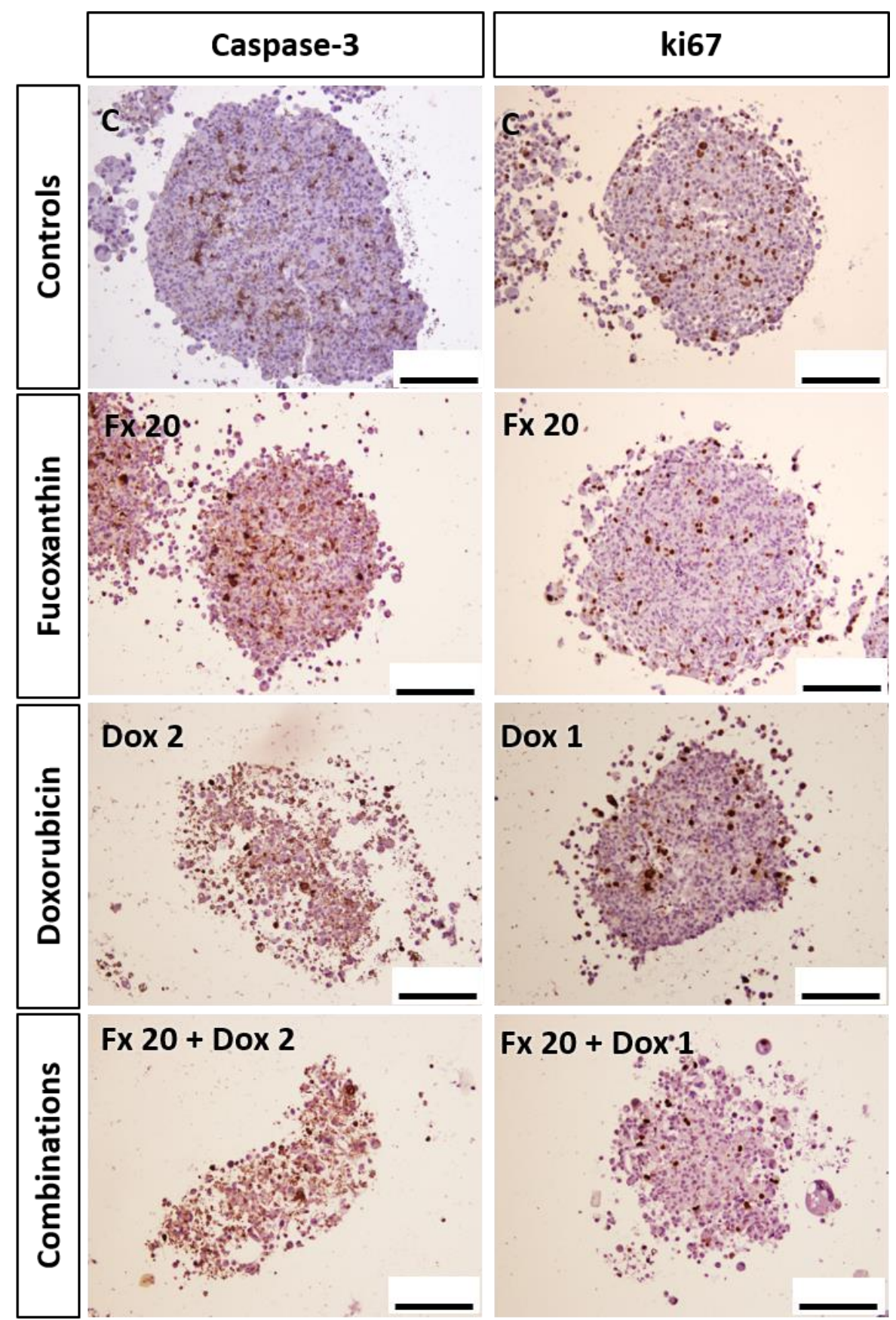

Figure 8. Representative images of ICC against caspase-3 and ki67 in the MDA-MB-231 MCAs exposed to Fx $(20 \mu \mathrm{M})$ and Dox $(1$ and $2 \mu \mathrm{M})$, alone and combined, for $96 \mathrm{~h}$. Brown staining corresponds to positive immunomarking. Scale bar: $100 \mu \mathrm{m}$.

Transmission Electron Microscopy (TEM)

The observation of the MCAs semithin sections revealed a subset of cells with high cytoplasmic lipid content. These cells were present in all tested conditions, even in the control group (Figure 9a,b). The study of the MCAs ultrathin sections confirmed a high amount of lipid droplets in some cells (Figure 9c). Generally, cells possessed very irregular nuclei, a cytoplasm rich in organelles, constituted mainly by Golgi apparatus, rough endoplasmic reticulum cisternae and irregularly shaped mitochondria (Figure 9c,d). 


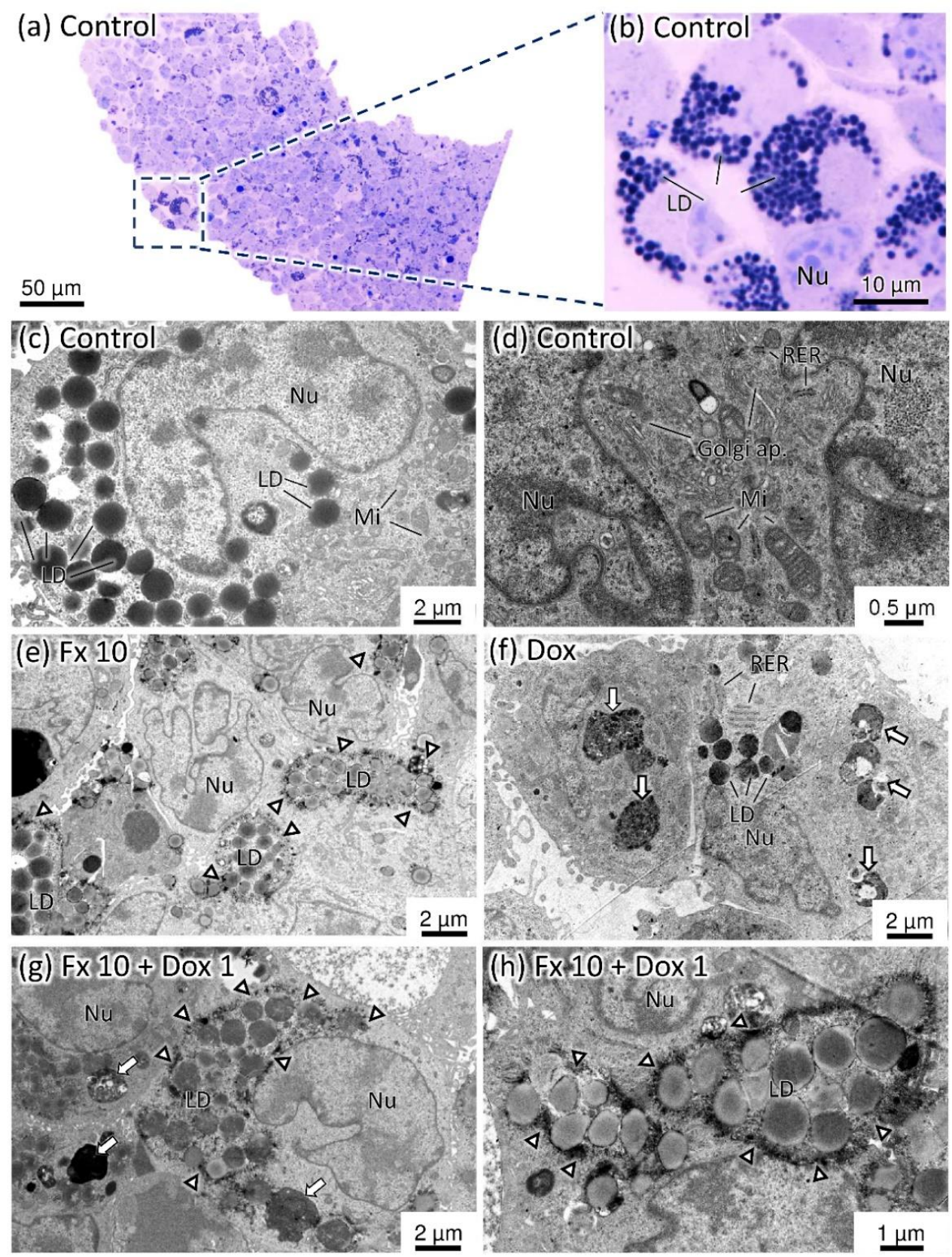

Figure 9. Representative images of semithin $(\mathbf{a}, \mathbf{b})$ and ultrathin sections (c-h) of MDA-MB-231 MCAs after $96 \mathrm{~h}$ of incubation. Golgi ap.-Golgi apparatus; LD—lipid droplets; Mi-mitochondria; $\mathrm{Nu}$-nucleus; RER - rough endoplasmic reticulum. The arrows indicate the autophagic vacuoles and arrowheads point to the electron-dense granular deposits around lipid droplets.

Figure $9 \mathrm{e}-\mathrm{h}$ illustrate the ultrastructural changes found in the most promising combination (Fx $10 \mu \mathrm{M}+$ Dox $1 \mu \mathrm{M})$.

The MCAs exposed to Dox alone and Dox combined exhibited cells with dense bodies and pleomorphic autophagic vacuoles (Figure $9 \mathrm{f}-\mathrm{h}$ ), which were more pronounced at the tested conditions that contained Dox $2 \mu \mathrm{M}$ and Dox $5 \mu \mathrm{M}$.

The MCAs exposed to Fx displayed lipid droplets too, but with a lower electron density when compared to those of the control and Dox alone. In these latter conditions, lipid droplets appeared as denser structures. Additionally, in the Fx exposed cells, there was a deposition of fine granular electron-dense material around the lipid droplets (arrowheads in Figure 9e,g,h). These deposits existed in all tested conditions that involved Fx, being more evident at Fx $20 \mu \mathrm{M}$. 
The MCAs treated with the combinations of Fx and Dox presented the same alterations observed in the MCAS exposed to each compound alone.

\section{Discussion}

Fucoxanthin has been considered as a promising anticancer compound. However, most of the available data regarding its effects derive from in vitro studies performed in 2D cultures, and its underlying mechanisms of action are not fully elucidated. Apart from this, there are just a few studies about its combinatory effects with reference anticancer drugs, especially in BC. Thus, our study aimed to bring new insights into the effects of Fx alone and in combination with two reference drugs (Dox and Cis) in a panel of 2D-cultured breast cell lines and investigate the most promising combination ( $\mathrm{Fx}+\mathrm{drug})$ in a more physiologically relevant in vitro model - the 3D cell culture. This study is the first to report the effects of Fx in combination with a chemotherapy drug in a BC 3D model.

Considering 2D cultures, Fx exerted cytotoxicity in all the cell lines (tumoral and non-tumoral) in a dose-dependent manner. Even though we found no studies in the literature for the SKBR3 BC cell line, several authors have reported the cytotoxic activities of Fx towards the MCF7 and MDA-MB-231 cells [14,23,51]. For instance, Rwigemera and colleagues stated that Fx promotes a dose-dependent decrease in the metabolic activity of MCF7 and MDA-MB-231 cells, at similar concentrations to the ones used herein [14]. The cytotoxic effects of Fx in the non-tumoral cells are controversial in the literature, since some authors claim the absence of Fx-induced effects on normal cells [21,52], while others as de La Mare and coworkers, showed that Fx at $10 \mu \mathrm{M}$ reduced the percentage survival of MCF12A cells to around 71\% [53]. Our results are in line with the latter one indicating that Fx is not specific to tumor cells since MCF12A cells were also affected.

According to our results, Fx did not induce cell death nor DNA damage detectable by the conducted assays. Nonetheless, some studies suggested that Fx caused apoptotic and genotoxic effects in BC cells $[14,23,51]$. When analyzing the existing reports, we noted that apart from the differences in the BC cell lines tested, some used different culture conditions, higher concentrations of $\mathrm{Fx}$, different exposure times, and/or distinct experimental methods for analyzing cell death and DNA damage.Besides, the used alkaline version of the comet assay only detects strand-breaks and alkali-labile sites [54], not excluding that other DNA damages might occur. All these factors might explain the divergent outcomes compared to our study.

Regarding the individual effects of the drugs in 2D cultures, Cis reduced the viability of all cell lines except the MDA-MB-231 cells. These results suggest that MDA-MB-231 is more resistant to Cis than other BC cell lines, as Leon-Galicia and colleagues reported [55]. Differently, Dox only showed cytotoxicity in MDA-MB-231 cells at the highest tested concentration. In agreement, other authors also reported cytotoxicity in the MDA-MB-231 cell line at the same Dox concentration [56]. Dox cytotoxicity seems to be correlated to the increase of DNA damages and consequently induction of cell death in MDA-MB-231 cells, concordantly with other reports with the same cell line $[57,58]$. Dox is known for causing DNA damage through several different mechanisms (e.g., DNA intercalation, topoisomerase II inhibition, ROS induction), which can trigger cell cycle arrest, impairment of mitochondrial function and cell death $[59,60]$.

Drug combinations bring several benefits in cancer treatment as they might, for instance, increase drug efficacy, decrease drug resistance and reduce the adverse effects. In this scenario, the combination of anticancer drugs with natural compounds has been reported in some clinical trials as a promising chemotherapeutic strategy [61]. In this study, the drug concentrations used in the combinatorial experiments were clinically relevant as they were similar to plasmatic concentrations found in oncological patients after intravenous infusion [62]. Besides, they were in line with other studies that used BC lines [63,64].

Our results showed that the combination of Fx with Dox promotes greater cytotoxic effects than each of the compounds separately on the SKBR3 and MDA-MB-231 cell lines. Interestingly, the most promising anticancer effects were noted for the combination $\mathrm{Fx}$ 
$10 \mu \mathrm{M}+$ Dox $1 \mu \mathrm{M}$ in the MDA-MB-231 cell line, representative of TNBC, the BC subtype where chemotherapy with drugs like Dox is the unique treatment option.

Recent reports have assessed the effects of Fx combined with conventional drugs in several types of cancer (e.g., leukaemia and colon cancer) $[42,44,65]$. However, data is almost non-existent in the context of BC, being, as far as we know, restricted to one study performed by Vijay and colleagues [43]. The latter supports our results, showing that the combination of Fx with Dox was more cytotoxic to MDA-MB-231 cells than the individual compounds. Also, in our study, the combination of Dox with Fx promoted genotoxicity and cell death in MDA-MB-231 cells, however, the effects were not different from Dox alone. These findings do not fully explain the increased cytotoxicity registered for this combination. One possible explanation for the observed effect might be the induction of cell cycle arrest since it is one of the mechanisms induced by Fx in different cancer cell lines [66,67]. Some reports also describe that the combination of carotenoids with ROS-inducing anticancer drugs like Dox, can act synergistically, enhancing the toxicity of the drug [68] which probably occur in this case, as Fx can also have a pro-oxidant action, increasing ROS, and consequently triggering cell death pathways [17,69].

Regardless of the inconclusive mechanistic data reported in $2 \mathrm{D}$, the most promising combination was explored in a more complex cell model-3D MCAs. Although many studies reported the effects of Fx in 2D cultures, in 3D cultures, as far as we investigated, the literature is limited to four studies [53,70-72]. Only de la Mare and collaborators reported Fx effects in a BC cell line cultured in 3D [53]. However, they aimed to test the impact of Fx on the formation of mammospheres and not in already formed 3D BC cultures. The scarce data on 3D cultures reinforces the need for more studies exploring the effects of Fx alone and combined with the chemotherapy drugs.

It seems now consensual that $3 \mathrm{D}$ cell cultures are more resistant to drug treatments and better translate organism-level realities $[73,74]$. That is why we prolonged the exposure time in MDA-MB-231 3D cultures and tested not only the most promising combination in 2D, but also higher Fx and Dox concentrations alone and in combination.

In the MTT assay, effects on cell viability were observed at Dox $1 \mu \mathrm{M}$ only when combined with Fx, and at higher concentrations of Dox, alone and combined. Otherwise, in the $\mathrm{LDH}$ assay, cytotoxic effects were only observed in two conditions: Fx $20 \mu \mathrm{M}+$ Dox $2 \mu \mathrm{M}$ and Dox $5 \mu \mathrm{M}$. The used viability tests (MTT and LDH) are both colorimetric assays, although they are based on two different approaches. The MTT assay relies on mitochondrial metabolic activity [75], while the LDH test evaluates plasmatic membrane integrity through the quantification of the LDH released from damaged cells [76]. MTT assay detected differences in cell viability at lower Dox and Fx concentrations, while in $\mathrm{LDH}$, only higher concentrations differed from the control. Thus, the differences in the detected cytotoxicity can be related to the different targets of these assays. The cytotoxic effect of the combination Fx with Dox obtained by the MTT, in 3D cultures, lined up with the results from 2D cultures.

A previous study from our group showed similar results to Dox's cytotoxicity in MDA-MB-231 cells [77]. Other authors tested Dox's concentrations that were from 10 [53] to 100 [78] times higher than the ones applied in our study, and surprisingly did not induce greater cytotoxicity.

Furthermore, the morphological evaluation by stereomicroscopy only revealed a significant increase in the area of the MCAs treated with the highest cytotoxic condition. Thus, no significant variations were detected for the conditions with a lower cytotoxicity degree, showing that the evaluation of the MCAs areas alone has not enough sensibility to detect cytotoxic effects.

The histological analysis of the HE-stained MCAs supports the results of the MTT assay. It was observed a deterioration in cell morphology of the MCAs treated with the conditions that statistically differed from the control in MTT. Additionally, the MCAs that revealed the highest degree of morphological damage presented cytotoxic effects that statistically differed from the control in both cytotoxic assays. 
Apoptosis is widely used to evaluate the cellular response to a chemotherapeutic agent [79], and caspase-3 is frequently employed as a biomarker of apoptosis [80]. The ICC evaluation of caspase- 3 expression showed that Fx alone did not differ from the control, similarly to $2 \mathrm{D}$ results from the nuclear condensation assay. The combination of Fx with Dox increased the percentage of caspase- 3 positive cells in relation to the drug alone, suggesting a possible pro-apoptotic effect of Fx. Previous studies also reported that Fx induces apoptosis in several cell lines [18,23,61], even in 3D models [72]. However, due to the non-existing data on the combined effects of Fx and Dox in 3D BC cultures, it was not possible to compare our results in such situations.

Additionally, the results of ICC for caspase-3 and MTT in 3D were very similar, as both experiments showed that $\mathrm{Fx}$ and Dox $1 \mu \mathrm{M}$ alone did not present differences in relation to the control, while Dox $\geq 1 \mu \mathrm{M}$ in combination with Fx revealed differences that show cell cytotoxicity and apoptosis induction. Once again, these findings reinforce the promising effects of combining Fx with Dox.

The effects on cell proliferation were evaluated using ki67, a well-known prognostic marker for BC [81], that is expressed in all phases of the cell cycle, except the G0 phase [82]. In 3D culture, Fx alone did not show effects on cellular proliferation, however, the combination of Fx $20 \mu \mathrm{M}$ with Dox $1 \mu \mathrm{M}$ augmented the drug effects, lowering cell proliferation to nearly half of the percentage of the compounds alone. These results point to a possible decrease in the cell proliferation caused by the combination of Fx and Dox. Still, further evaluation of the cell cycle will be necessary to elucidate this topic.

The histological analysis complemented with ICC unveiled as a useful tool for evaluating the cytotoxicity of the tested compounds, not only for corroboration of the cytotoxic assays and verifying the proliferation and apoptotic status, but also to give a general view of the morphology of the MCAs, verify the existence of necrotic cores, and correlate the ICC markers with their localization into the MCAs. An additional advantage of processing MCAs for paraffin embedding is the possibility of having the biological samples in a form that can be stored indefinitely and generate sections for different ICC markers or even extract genetic material for further studies.

The ultrastructural analysis revealed that MDA-MB-231 MCAs presented a pool of cells with high lipid droplets content, not noticeable in paraffin sections due to lipid dissolution during the processing. These lipid droplets were previously reported in this cell line, and the authors described that the sub-population of highly enriched lipid cells was related to stemness features [83]. In MCAs exposed to Fx (alone and combined), a lower electron density of the lipid droplets was observed. Knowing that the electron density of lipid droplets reflects fatty acid composition [84], this can indicate that Fx can influence the composition of the lipid droplets. Additionally, it was noted a deposition of a granular electron-dense material around the lipid droplets. The explanation of such changes needs to be investigated, however, it could be related to lipidic trafficking as Fx is described as a regulator of pathways related to fatty acid synthesis, lipolysis, and thermogenesis [85]. Indeed, the presence of lipid droplets is thought to be part of stress response to treatments, regulation of proliferation, migration and survival of cancer cells [86]. The additional presence of a great number of autophagic vacuoles in the cytoplasm indicates that Dox induced autophagy in the MDA-MB-231 cell line, which agrees with a previous report [87].

In summary, our results indicated that Fx alone had cytotoxic effects in all the 2Dcultured breast cell lines. In combination with Dox, Fx suggestively potentiated the drug effect in SKBR3 and MDA-MB-231 cells, being these effects more pronounced in the TNBC cell line. However, the mechanisms behind the enhanced cytotoxicity need further elucidation, since in addition to DNA damage and cell death induction, other mechanisms as cell cycle arrest, ROS induction and alteration of lipid metabolism may occur.

Besides being more resistant to Fx and Dox alone, 3D cultures also presented higher cytotoxic effects in the combination of Dox with Fx, corroborating the 2D results. The cytotoxicity in 3D was supported by the morphological analysis (light and electron microscopy) and ICC. Apart from increasing the number of apoptotic cells and lowering cell prolifera- 
tion, the combination of Fx and Dox damaged the MCAs histological structure and caused ultrastructural alterations. These findings reinforce the utility of using a multi-endpoint approach for evaluating the cytotoxic effects of compounds.

Our data from 2D and 3D cultures suggest that Fx has potential as a drug adjuvant inTNBC treatment when Dox is applied for chemotherapy. Notwithstanding, more in vitro and in vivo studies are necessary to explore the underlying mechanisms of action of Fx and its combination with Dox.

\section{Materials and Methods}

\subsection{Chemicals}

3-(4,5-Dimethyl-2-thiazolyl)-2,5-diphenyl-2H-tetrazolium bromide (MTT), 4',6diamidino-2-phenylindole (DAPI), cisplatin, cholera toxin, doxorubicin, epidermal growth factor receptor (EGFR), fucoxanthin, hydrocortisone, insulin, low and normal melting agarose and triton X-100 were obtained from Sigma Aldrich (St. Louis, MO, USA). Dimethyl sulfoxide (DMSO) was purchased from VWR Chemicals (Solon, OH, USA). Dulbecco's modified Eagle's medium (DMEM) high glucose without glutamine and phenol red, fetal bovine serum (FBS), streptomycin-penicillin and trypsin-ethylenediaminetetraacetic acid (EDTA) solution were acquired from Biochrom KG (Berlin, Germany). Dulbecco's modified Eagle's medium/Ham's nutrient mixture F12 (DMEM/F12) medium without phenol red was obtained from GE Healthcare (Chicago, IL, USA). All the other reagents and chemicals used were analytical grade.

\subsection{Stock and Exposure Solutions}

Stock solutions of Dox and Fx were prepared in DMSO and the stock solution of Cis was prepared in $0.9 \% \mathrm{NaCl}$ solution. All stock solutions were kept at $-20{ }^{\circ} \mathrm{C}$ before use, except Cis stock solution that was kept at $4{ }^{\circ} \mathrm{C}$ for up to 1 month. Exposure solutions were always prepared before experiments by diluting the appropriate volume of each compound stock solution into the respective supplemented fresh culture medium (DMEM or DMEM/F12 medium, dependent on the cell line).

\subsection{Cell Culture}

\subsubsection{D Cell Culture}

The MDA-MB-231, SKBR3 and MCF12A cell lines were purchased from the American Tissue Culture Collection (ATCC) and the MCF7 cell line was acquired from the European Collection of Authenticated Cell Cultures (ECACC). MCF12A is a non-tumor breast cell line, while the others are tumor cell lines representative of different BC subtypes: MCF7Luminal A; SKBR3-HER-2 subtype; MDA-MB-231—TNBC [88,89]. MCF7, SKBR3 and MDA-MB-231 cells were cultured in high glucose DMEM deprived of phenol red and supplemented with $10 \%$ of FBS and $1 \%$ of the streptomycin-penicillin solution. MCF12A cells were cultured in DMEM/F12 supplemented with $20 \mathrm{ng} / \mathrm{mL}$ of EGFR, $100 \mathrm{ng} / \mathrm{mL}$ of cholera toxin, $0.01 \mathrm{mg} / \mathrm{mL}$ of human insulin and $500 \mathrm{ng} / \mathrm{mL}$ hydrocortisone, 10\% FBS and 1\% of streptomycin-penicillin solution. All the cell lines were maintained as monolayer cultures in $775 \mathrm{~cm}^{2}$ culture flasks (Orange Scientific, Belgium) and incubated under standard cell culture conditions $\left(37^{\circ} \mathrm{C}, 5 \% \mathrm{CO}_{2}\right)$. When reaching approximately $80 \%$ confluence, cells were subcultured using $0.25 \%$ trypsin/EDTA at $37^{\circ} \mathrm{C}$, counted in a hemocytometer and assessed for their viability using the standard trypan blue staining procedure. All experiments were conducted with cells at passages under 40 .

\subsubsection{D Cell Culture-Multicellular Aggregates (MCAs)}

MCAs were formed in ultra-low attachment plates (Corning Inc., Corning, NY, USA) as described in a previous report [90]. Cells were seeded at $40 \times 10^{4}$ cells $/ \mathrm{mL}, 200 \mu \mathrm{L}$ per well, and MCAs were formed after $72 \mathrm{~h}$ of incubation at $37^{\circ} \mathrm{C}, 5 \% \mathrm{CO}_{2}$. 


\subsection{Study Design}

Experiments were conducted according to the study design represented in Figure 10. First, in Phase 1, the cytotoxic effects of four concentrations of Fx $(1 ; 10 ; 20$ and $50 \mu \mathrm{M})$ were screened by the MTT assay in the panel of breast cell lines cultured in 2D. Considering the results obtained in Phase 1, two concentrations of Fx were selected to be tested in combination with two reference drugs (Cis and Dox) in Phase 2 (Table 1). For each cell line, one concentration of Fx was selected with no statistical effect on cell viability and another that did not reduce the cell viability below $50 \%$ (on average). The drug concentrations were chosen according to the results of a recent report [77]. Only the concentrations with no effects or that did not affect cell viability by more than $50 \%$ were selected for our study. As in Phase 1, in Phase 2 the cytotoxic effects of the combinations and respective isolated compounds were also assessed by the MTT assay on the 2D-cultured breast cell lines. According to the results obtained in Phase 2, we selected the most promising combination, that is, the one with the highest cytotoxic effects that statistically differed from the control and both isolated compounds. This combination and constituent compounds were further explored in the respective cell line, during Phases 3 and 4. In Phase 3, the nuclear condensation and comet assays were conducted on 2D cultures to study the potential mechanisms behind the induced cytotoxicity. In Phase 4 , the combination and respective individual compounds were tested on 3D cultures at equal and higher concentrations than the ones tested in the 2D cultures. The effects were evaluated using a combination of functional and morphological methodologies, including cytotoxic assays (MTT and LDH assays), stereomicroscopy, hematoxylin and eosin (HE) staining, immunocytochemistry (ICC) and transmission electron microscopy (TEM).

Table 1. Tested concentrations of Fx, Cis and Dox in the combinatorial experiments.

\begin{tabular}{ccccc}
\hline \hline Cell Line & Compound & $\begin{array}{c}\text { Fucoxanthin } \\
(\mathbf{F x})\end{array}$ & Cisplatin (Cis) & Doxorubicin (Dox) \\
\hline & & & \\
MCF7 & $1 ; 10 \mu \mathrm{M}$ & $10 ; 20 \mu \mathrm{M}$ & $0.01 ; 0.1 \mu \mathrm{M}$ \\
SKBR3 & & $1 ; 10 \mu \mathrm{M}$ & $0.1 ; 1 \mu \mathrm{M}$ \\
MA-MB-231 & & $01 ; 0.1 \mu \mathrm{M}$ \\
\hline
\end{tabular}

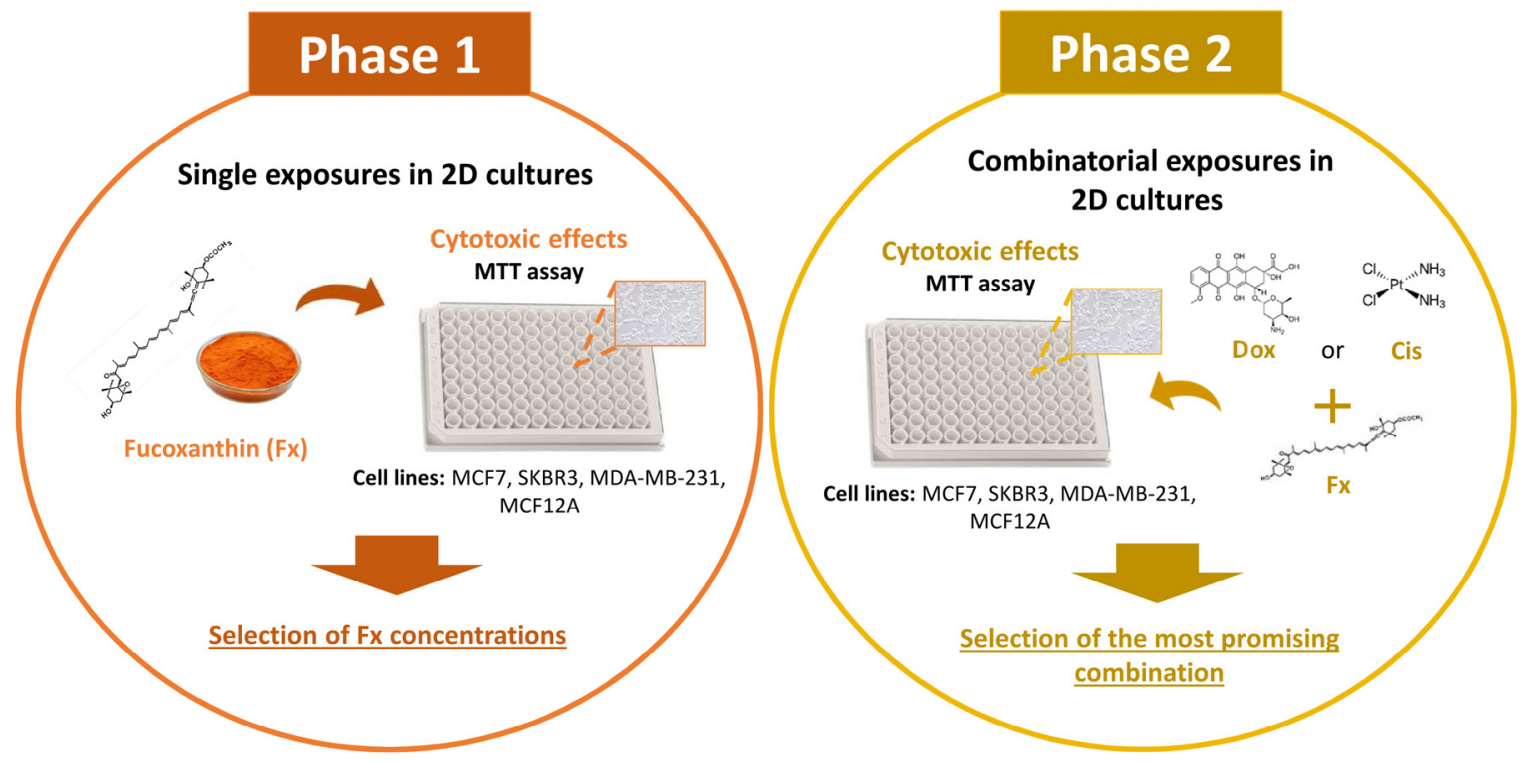

Figure 10. Conts. 


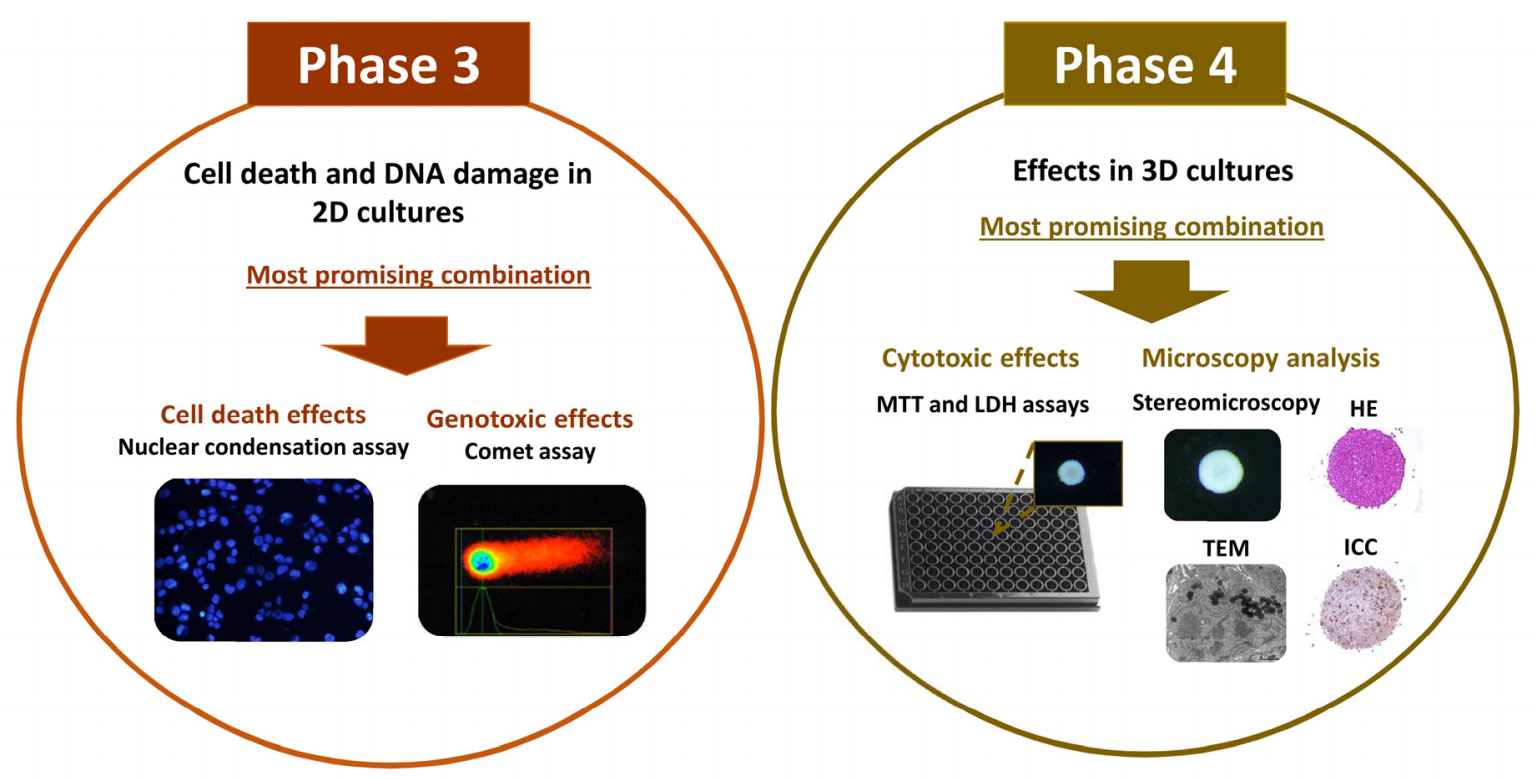

Figure 10. Schematic representation of the study design. HE: hematoxylin and eosin; ICC: immunohistochemistry and TEM: transmission electron microscopy.

In all the experiments, control cells (negative control) were incubated in a culture medium with $0.1 \%$ DMSO.

\subsection{Exposures (Single or Combination) in 2D Cell Cultures 4.5.1. MTT Assay}

Cells were seeded in 96-multiwell culture plates (Orange Scientific, Braine-l'Alleud, Belgium) at a density of $0.5 \times 10^{5}$ cells $/ \mathrm{mL}(100 \mu \mathrm{L} /$ well) and left to adhere for $24 \mathrm{~h}$. Then, cells were exposed for $72 \mathrm{~h}$ to different concentrations of Fx alone (Phase 1 ) and in combination with Dox or Cis (Phase 2). After the exposure, $10 \mu \mathrm{L}(0.5 \mathrm{mg} / \mathrm{mL})$ of MTT stock reagent was added to the wells, and the microplate was incubated for $2 \mathrm{~h}$ at $37^{\circ} \mathrm{C}, 5 \%$ $\mathrm{CO}_{2}$. The medium was then removed, and the formazan crystals were dissolved in $150 \mu \mathrm{L}$ of DMSO under slight agitation for $30 \mathrm{~min}$ in the dark. Absorbance (A) was measured at $570 \mathrm{~nm}$ using a microplate reader Multiskan GO (Thermo Fisher Scientific, Waltman, MA, USA). Results were expressed as \% of cell viability relative to the control-an average of five to six independent experiments performed in triplicate-and calculated according to the following equation:

$$
\text { Cell viability }(\%)=\left(\mathrm{A}_{\text {Sample }} \div \mathrm{A}_{\text {Control }}\right) \times 100
$$

\subsubsection{Nuclear Condensation Assay}

Cells were seeded $(1000 \mu \mathrm{L} /$ well) in 24-multiwell culture plates (Orange Scientific, Belgium) at a density of $0.5 \times 10^{5}$ cells $/ \mathrm{mL}$ and incubated for $24 \mathrm{~h}$ under standard cell culture conditions. Cells were then exposed for $72 \mathrm{~h}$ to the most promising combination selected in Phase 2 and respective isolated compounds. Briefly, both adherent and non-adherent cells were collected, washed, centrifuged and fixated with $4 \%(w / v)$ paraformaldehyde (Sigma Aldrich, St. Louis, MO, USA) in PBS. Then, cells were placed onto silane adhesive microscope slides (VWR International B.V, Amsterdam, The Netherlands) by cytocentrifugation using Shandon Cytospin 3 cytocentrifuge (Thermo Fisher Scientific, Waltham, MA, USA) at $28 \times g$ for $5 \mathrm{~min}$. Slides were incubated with DAPI staining solution $(1 \mu \mathrm{g} / \mathrm{mL})$ for $10 \mathrm{~min}$ in the dark and after incubation, at least 300 cells per sample were counted under a fluorescence microscope (Olympus IX71, Tokyo, Japan) using the total magnification of $200 \times(20 \times$ objective lens plus $10 \times$ eyepiece lens $)$. The results were expressed as percent- 
age of condensed nuclei-an average of three to five independent experiments, with one replicate per condition-and calculated according to the following equation:

$\%$ Condensed nuclei $=($ No. cells with nuclear condensation $\div$ No. total cells $) \times 100$

\subsubsection{Comet Assay}

Cells were seeded at $0.5 \times 10^{5}$ cells $/ \mathrm{mL}(1000 \mu \mathrm{L} /$ well $)$ in 24 -multiwell culture plates and allowed to adhere for $24 \mathrm{~h}$, under standard conditions. Subsequently, cells were treated for $2 \mathrm{~h}$ with the test conditions and by the end of the treatments they were washed with PBS, trypsinized with $0.25 \%$ Trypsin/EDTA solution, collected and centrifuged at $1700 \times g$ for 1 min using the Micro Star 12 microcentrifuge (VWR International, Pennsylvania, USA). After centrifugation and removal of the supernatant, the cells were mixed with $0.5 \%(w / v)$ Low Melting Point Agarose and transferred to microscope slides previously coated with $1 \%(w / v)$ Normal Melting Point Agarose. Slides were immediately covered with glass coverslips (Thermo Fisher Scientific, Waltham, MA, USA) and maintained at $4{ }^{\circ} \mathrm{C}$ for $10 \mathrm{~min}$. Then, the coverslips were removed, and slides were incubated in a lysis solution [2.5 M NaCl, $100 \mathrm{mM} \mathrm{Na} 2$ EDTA, $10 \mathrm{mM}$ Tris Base, pH 10 plus 1\% ( $v / v$ ) Triton $\mathrm{X}-100, \mathrm{pH} 10$ ] for $1 \mathrm{~h}$, at $4{ }^{\circ} \mathrm{C}$, to lysate the cells and release the DNA. Subsequently, slides were washed with distilled water, transferred into a horizontal electrophoresis tank, and immersed in electrophoresis buffer ( $300 \mathrm{mM} \mathrm{NaOH}$ and $1 \mathrm{mM} \mathrm{Na} \mathrm{a}_{2}$ ETA, $\left.\mathrm{pH} \geq 13\right)$ for $40 \mathrm{~min}$ at $4{ }^{\circ} \mathrm{C}$ for DNA unwinding. Electrophoresis ran for $20 \mathrm{~min}$ at $4{ }^{\circ} \mathrm{C}$ under a voltage gradient of $1 \mathrm{~V}$ per $\mathrm{cm}(20 \mathrm{~V})$. Following electrophoresis, slides were rinsed in distilled water, dehydrated with absolute ethanol, and lastly air-dried. Before analysis, slides were rehydrated in $25 \mathrm{~mL}$ of Tris-EDTA (TE) Buffer (Tris-HCl $10 \mathrm{mM}$ and EDTA $1 \mathrm{mM}$ ) for 15 min under slight agitation, and then $20 \mu \mathrm{L}$ of SYBR Gold (Thermo Fisher Scientific, Waltman, MA, USA) was added to the TE buffer for DNA staining. Slides were incubated for $30 \mathrm{~min}$ in the dark under slight agitation. After staining, slides were analyzed with a Nikon Eclipse E400 microscope (Nikon, Tokyo, Japan) connected to an epi-fluorescence illuminator Nikon C-SHG1 power supply for HG $100 \mathrm{~W}$ with $250 \times$ magnification (Semrock SYBRGold-A-NQF filter, Rochester, NY, USA). Samples were analyzed by the Comet Assay $\mathrm{IV}^{\mathrm{TM}}$ software (Perceptive Instruments, Haverhill, UK) and the parameter "tail intensity" (percentage of DNA in the comet tail) was used to evaluate the DNA damages. A hundred randomly selected nucleoids were analyzed per sample. Results were expressed as the mean of three independent experiments, with one replicate per condition.

\subsection{Exposures (Single or Combination) in 3D Cell Cultures}

MCAs were exposed to Fx alone and combined with Dox for $96 \mathrm{~h}$ under standard cell culture conditions. Cells treated with $0.1 \%$ DMSO and Dox $5 \mu \mathrm{M}$ were included as a negative and positive control, respectively.

\subsubsection{MTT Assay}

The MTT assay was performed as previously described for monolayer cultures, with slight modifications. MCAs were incubated in the dark at $37^{\circ} \mathrm{C}$ in a $5 \% \mathrm{CO}_{2}$ atmosphere with $20 \mu \mathrm{L}$ of the MTT stock solution per well for $4 \mathrm{~h}$. After incubation, the MCAs were transferred from the ULA 96-well microplates into 96-well flat-bottomed microplates and the medium was removed. Formazan crystals were dissolved in $150 \mu \mathrm{L}$ of DMSO and after 30 min under slight agitation in the dark, absorbance measurements were performed. The cell viability percentages were calculated according to the formula mentioned above. The results were expressed as the mean of five independent experiments performed in triplicate.

\subsubsection{Lactate Dehydrogenase (LDH) Assay}

LDH assay was performed using the LDH Cytotoxicity Assay Kit (Enzo Life Sciences, Lausen, Switzerland) according to the manufacturer's instructions. The medium from the treated conditions, high control (maximum LDH release by applying the lysis buffer) and negative control wells were transferred to a flat-bottom 96-well microplate. Then, the working 
solution from the LDH kit was added and after the incubation period, the reaction was terminated by the stop solution. Absorbance (A) was measured at $490 \mathrm{~nm}$ in a microplate reader Multiskan GO (Thermo Fisher Scientific, Waltman, MA, USA). The results were expressed as percentage of cytotoxicity based on the LDH release-mean of five independent experiments performed in triplicate- and calculated using the following equation:

Cytotoxicity $(\%)=\left(A_{\text {test substance }}-A_{\text {negative control }}\right) \div\left(A_{\text {high control }}-A_{\text {negative control }}\right) \times 100$

\subsubsection{Stereomicroscopic Analysis and Area Measurements}

MCAs were photographed at the end of the exposure (96 h) using an Olympus SZX10 stereomicroscope, equipped with a digital camera DP21 (Olympus, Tokyo, Japan). Stereomicroscope images were analyzed by the free download AnaSP software [91] that measured the MCAs areas. Results were expressed as the mean of four independent experiments performed in triplicate.

\subsubsection{Hematoxylin and Eosin (HE) Staining}

MCAs were fixed, harvested, processed, embedded in paraffin blocks and ultimately sectioned as previously described [77]. The obtained slides were selected and divided for standard HE staining and immunocytochemistry (ICC). For HE, sections were deparaffinized in xylene (twice, $10 \mathrm{~min}$ each), rehydrated in descending alcoholic concentration solutions (absolute ethanol, ethanol 95\% and ethanol 70\%, 5 min each) and rinsed in running tap water. Then, sections were stained with Mayer's hematoxylin (Merck, Darmstadt, Germany) for $2 \mathrm{~min}$, rinsed in tap water, stained with eosin Y $1 \%$ aqueous solution (Merck, Darmstadt, Germany) for 5 min and newly washed in tap water. Following the HE staining, sections were dehydrated in absolute ethanol (thrice, 5 min each) and diaphanized in xylene (twice, 3 min each). Finally, slides were mounted using Coverquick 2000 mounting medium (VWR International, France). Representative images of MCAs sections were taken using a DP21 camera (Olympus, Tokyo, Japan) linked to an Olympus BX50 microscope (Olympus, Tokyo, Japan).

\subsubsection{Immunocytochemical Analysis}

ICC was performed using ki67 and caspase-3 as proliferation [92] and apoptosis [93] markers, respectively. Sections of the paraffin-embedded MCAs were deparaffinized and hydrated as described for the HE staining protocol. The heat antigen retrieval step was performed in a pressure cooker by placing the slides in boiling citrate buffer $(0.01 \mathrm{M}$, $\mathrm{pH}$ 6.0) for $2 \mathrm{~min}$ after reaching the maximum pressure. After cooling and rinsing with distilled water, slides were immersed for $10 \mathrm{~min}$ in a solution of $3 \%$ hydrogen peroxide in methanol to block endogenous peroxidase activity and rinsed in tris-buffered saline (TBS, pH 7.6). Briefly, unspecific antibody binding was blocked for 5 min using the Protein block reagent from the NovoLinkTM Max Polymer Detection System Kit (Leica Biosystems, Nussloch, Germany) and the sections were rinsed with TBS (twice, 5 min each). Thereafter, the sections were incubated for $2 \mathrm{~h}$ in a humidified chamber at room temperature with the following primary antibodies: Rabbit monoclonal anti-Ki67, clone SP6 (Biocare Medical, Pacheco, CA, USA), dilution of 1:200; rabbit polyclonal anti-caspase-3, ab 13847 (Abcam, Cambridge, UK), dilution 1:5000. All the primary antibodies were diluted in PBS with 5\% bovine serum albumin (BSA) (Nzytech, Lisbon, Portugal). As a negative control, sections were incubated in PBS with 5\% BSA solution under the same conditions. After incubation, sections were rinsed (twice, 5 min each) in TBST (TBS with 0.05\% Tween 20) (Sigma Aldrich, St.Louis, MO, USA), incubated for 30 min with the Post Primary solution from the kit and again washed with TBST. Slides were incubated with the NovoLinkTM Polymer reagent (30 min), washed in TBST (twice, 5 min each) incubated with DAB (3,3'-diaminobenzidine) working solution from the kit for signal revelation ( $2 \mathrm{~min}$ ) and rinsed in tap water. Lastly, slides were counterstained with Mayer's hematoxylin (Merck, Darmstadt, Germany) for $1 \mathrm{~min}$, washed in tap water, dehydrated in ethanol, cleared in xylene and coverslipped with Coverquick 2000 mounting medium (VWR International, Fontenay sous Bois, France). 
In every independent experiment, one representative image of a single MCA per test condition was captured using an Olympus BX50 microscope (Olympus, Tokyo, Japan) attached to a DP21 camera (Olympus, Tokyo, Japan). From those images, a quantification of the percentage of positive immunomarked cells was calculated by superimposing a grid for preventing the edging effects. A total of 200-800 cells were counted per condition (fewer cells were counted in high cytotoxicity treatments due to cell loss).

\subsubsection{Transmission Electron Microscopy (TEM)}

MCAs were processed for TEM to assess their ultrastructural morphology. Fixation was conducted with $2.5 \%$ Glutaraldehyde in Cacodylate buffer $(0.15 \mathrm{M}, \mathrm{pH} 7.2)$ for $2 \mathrm{~h}$, and then the MCAs were washed twice in Cacodylatebuffer (30 min each). Post-fixation was performed with 1\% osmium tetroxide (Agar Scientific, Stansted, UK) in Cacodylate buffer for $2 \mathrm{~h}$. MCAs were then washed with the same buffer and dehydrated in graded ethanol series up to $100 \%$ ( $50 \%$ ethanol; $70 \%$ ethanol; $95 \%$ ethanol; absolute ethanol; absolute ethanol-30 min each). Until this step, all procedures were conducted at $4^{\circ} \mathrm{C}$. Then, MCAs were placed at room temperature and the dehydrating agent was replaced for propylene oxide (Merck, Darmstadt, Germany) (two baths of $30 \mathrm{~min}$ each). Following the resin impregnation, MCAs were subjected to three mixtures of propylene oxide and epoxy resin with increasing resin concentration (propylene oxide + epon $3: 1 ; 1: 1 ; 1: 3-1$ h each mixture) and ultimately embedded in only resin (epon $-1 \mathrm{~h}$; epon-10 min at $60^{\circ} \mathrm{C}$ ). After, TEM blocks were obtained by placing the MCAs in rubber molds and then tranferringing them to the oven where they stayed for $48 \mathrm{~h}$ at $60^{\circ} \mathrm{C}$ for resin polymerization. Semithin $(1.25 \mu \mathrm{m})$ and ultrathin $(90 \mathrm{~nm})$ sections were obtained with a diamond knife (Diatome, Nidau, Switzerland) on an ultramicrotome EM UC7 (Leica, Nussloch, Germany). Ultrathin sections were placed on 200 mesh hexagonal copper grids (Agar Scientific, Stansted, UK) and contrasted with $3 \%$ aqueous uranyl acetate (20 min) (Merck, Darmstadt, Germany) and Reynolds' lead citrate (10 min) (Merck, Darmstadt, Germany). Grids were analyzed under an electron microscope JEOL 100CXII (JEOL, Tokyo, Japan), operated at $60 \mathrm{kV}$, and photographs of representative ultrastructural features were taken with the Orius SC1000 CCD digital camera (Gatan, Pleasanton, CA, USA).

\subsection{Statistical Analysis}

The descriptive and analytical statistics were performed with Past3 (version 3.19) freeware [94] and GraphPad Prism 6.0 software (GraphPad Software, La Jolla, CA, USA). The normality and homogeneity of variance were tested by the Shapiro-Wilk and the Levene tests, respectively. All the results were obtained from at least three independent experiments and expressed as mean + standard deviation (SD), except for the MCAs areas that were presented in median, maximum, minimum, and interquartile range (Q3-Q1). Significant differences $(p<0.05)$ were assessed by one-way ANOVA, followed by the post hoc Holm-Šídák multiple comparison test. In selected cases, the significance of the difference between two groups of interest was tested using the Student's t-test together with the sequential Holm-Bonferroni correction. The latter was applied via a free spreadsheet calculator $[95,96]$.

Author Contributions: Conceptualization by F.M., A.C.M., A.A.R. and E.R.; methodology by A.C.M., F.M., C.C., A.A.R. and E.R.; formal analysis by A.C.M., F.M. and A.A.R.; investigation by A.C.M. and F.M.; resources by C.C. and E.R.; writing-original draft preparation by A.C.M. and F.M.; writingreview and editing by A.C.M., F.M., C.C., A.A.R. and E.R.; visualization by A.C.M., F.M., C.C., A.A.R. and E.R.; supervision by A.A.R. and E.R.; project administration by E.R.; funding acquisition by E.R. All authors have read and agreed to the published version of the manuscript.

Funding: The Strategic Funding UIDB/04423/2020 and UIDP/04423/2020 partially supported this research, through national funds provided by FCT and ERDF to CIIMAR/CIMAR, in the framework of the program PT2020. The Doctoral Program in Biomedical Sciences, of the ICBAS-University of Porto, offered additional funds.

Institutional Review Board Statement: Not applicable. 
Informed Consent Statement: Not applicable.

Data Availability Statement: The data presented in this study are available on request from the corresponding author.

Conflicts of Interest: The authors declare no conflict of interest.

Sample Availability: Not available.

\section{References}

1. Newman, D.J.; Cragg, G.M. Natural products as sources of new drugs from 1981 to 2014. J. Nat. Prod. 2016, 79, 629-661. [CrossRef]

2. Wright, G.D. Unlocking the potential of natural products in drug discovery. Microb. Biotechnol. 2019, 12, 55-57. [CrossRef] [PubMed]

3. Sharifi-Rad, J.; Ozleyen, A.; Boyunegmez Tumer, T.; Oluwaseun Adetunji, C.; El Omari, N.; Balahbib, A.; Taheri, Y.; Bouyahya, A.; Martorell, M.; Martins, N.; et al. Natural products and synthetic analogs as a source of antitumor drugs. Biomolecules 2019, 9, 679. [CrossRef]

4. Ruan, B.F.; Ge, W.W.; Lin, M.X.; Li, Q.S. A review of the components of seaweeds as potential candidates in cancer therapy. Curr. Med. Chem. Anticancer Agents 2018, 18, 354-366. [CrossRef]

5. Schumacher, M.; Kelkel, M.; Dicato, M.; Diederich, M. Gold from the sea: Marine compounds as inhibitors of the hallmarks of cancer. Biotechnol. Adv. 2011, 29, 531-547. [CrossRef]

6. Proksch, P.; Edrada-Ebel, R.; Ebel, R. Drugs from the sea-Opportunities and obstacles. Mar. Drugs 2003, 1, 5-17. [CrossRef]

7. Khalifa, S.A.M.; Elias, N.; Farag, M.A.; Chen, L.; Saeed, A.; Hegazy, M.F.; Moustafa, M.S.; Abd El-Wahed, A.; Al-Mousawi, S.M.; Musharraf, S.G.; et al. Marine natural products: A source of novel anticancer drugs. Mar. Drugs 2019, 17, 491. [CrossRef]

8. Jimenez, P.C.; Wilke, D.V.; Branco, P.C.; Bauermeister, A.; Rezende-Teixeira, P.; Gaudêncio, S.P.; Costa-Lotufo, L.V. Enriching cancer pharmacology with drugs of marine origin. Br. J. Pharmacol. 2020, 177, 3-27. [CrossRef]

9. Dyshlovoy, S.A.; Honecker, F. Marine compounds and cancer: The first two decades of XXI century. Mar. Drugs 2019, 18, 20. [CrossRef] [PubMed]

10. Khalid, S.; Abbas, M.; Saeed, F.; Bader-Ul-Ain, H.; Ansar Rasul Suleria, H. Therapeutic potential of seaweed bioactive compounds. In Seaweed Biomaterials; Maiti, S., Ed.; IntechOpen: London, UK, 2018; pp. 8-25. [CrossRef]

11. Teas, J.; Vena, S.; Cone, D.L.; Irhimeh, M. The consumption of seaweed as a protective factor in the etiology of breast cancer: Proof of principle. J. Appl. Phycol. 2013, 25, 771-779. [CrossRef] [PubMed]

12. Yang, Y.J.; Nam, S.-J.; Kong, G.; Kim, M.K. A case-control study on seaweed consumption and the risk of breast cancer. Br. J. Nutr. 2010, 103, 1345-1353. [CrossRef]

13. Funahashi, H.; Imai, T.; Mase, T.; Sekiya, M.; Yokoi, K.; Hayashi, H.; Shibata, A.; Hayashi, T.; Nishikawa, M.; Suda, N.; et al. Seaweed prevents breast cancer? Jpn. J. Cancer Res. 2001, 92, 483-487. [CrossRef]

14. Rwigemera, A.; Mamelona, J.; Martin, L.J. Inhibitory effects of fucoxanthinol on the viability of human breast cancer cell lines MCF-7 and MDA-MB-231 are correlated with modulation of the NF-kappaB pathway. Cell Biol. Toxicol. 2014, 30, 157-167. [CrossRef]

15. Bae, M.; Kim, M.B.; Park, Y.K.; Lee, J.Y. Health benefits of fucoxanthin in the prevention of chronic diseases. Biochim. Biophys. Acta Mol. Cell Biol. Lipids 2020, 1865, 158618. [CrossRef]

16. Martin, L.J. Fucoxanthin and its metabolite fucoxanthinol in cancer prevention and treatment. Mar. Drugs 2015, 13, 4784-4798. [CrossRef]

17. Kumar, S.R.; Hosokawa, M.; Miyashita, K. Fucoxanthin: A marine carotenoid exerting anti-cancer effects by affecting multiple mechanisms. Mar. Drugs 2013, 11, 5130-5147. [CrossRef]

18. Meresse, S.; Fodil, M.; Fleury, F.; Chenais, B. Fucoxanthin, a marine-derived carotenoid from brown seaweeds and microalgae: A promising bioactive compound for cancer therapy. Int. J. Mol. Sci. 2020, 21, 9273. [CrossRef]

19. Garg, S.; Afzal, S.; Elwakeel, A.; Sharma, D.; Radhakrishnan, N.; Dhanjal, J.K.; Sundar, D.; Kaul, S.C.; Wadhwa, R. Marine carotenoid fucoxanthin possesses anti-metastasis activity: Molecular evidence. Mar. Drugs 2019, 17, 338. [CrossRef]

20. Zhang, H.; Tang, Y.; Zhang, Y.; Zhang, S.; Qu, J.; Wang, X.; Kong, R.; Han, C.; Liu, Z. Fucoxanthin: A promising medicinal and nutritional ingredient. Evid. Based Complement. Alternat. Med. 2015, 2015, 723515. [CrossRef]

21. Ishikawa, C.; Tafuku, S.; Kadekaru, T.; Sawada, S.; Tomita, M.; Okudaira, T.; Nakazato, T.; Toda, T.; Uchihara, J.N.; Taira, N.; et al. Anti-adult T-cell leukemia effects of brown algae fucoxanthin and its deacetylated product, fucoxanthinol. Int. J. Cancer 2008, 123, 2702-2712. [CrossRef]

22. Satomi, Y. Antitumor and cancer-preventative function of fucoxanthin: A marine carotenoid. Anticancer Res. 2017, 37, 1557-1562. [CrossRef]

23. Rwigemera, A.; Mamelona, J.; Martin, L.J. Comparative effects between fucoxanthinol and its precursor fucoxanthin on viability and apoptosis of breast cancer cell lines MCF-7 and MDA-MB-231. Anticancer Res. 2015, 35, 207-219. [PubMed]

24. Wang, J.; Jiang, Y.-F. Natural compounds as anticancer agents: Experimental evidence. World J. Exp. Med. 2012, 2, 45-57. [CrossRef] [PubMed]

25. Wang, J.; Ma, Y.; Yang, J.; Jin, L.; Gao, Z.; Xue, L.; Hou, L.; Sui, L.; Liu, J.; Zou, X. Fucoxanthin inhibits tumour-related lymphangiogenesis and growth of breast cancer. J. Cell Mol. Med. 2019, 23, 2219-2229. [CrossRef]

26. Sung, H.; Ferlay, J.; Siegel, R.L.; Laversanne, M.; Soerjomataram, I.; Jemal, A.; Bray, F. Global cancer statistics 2020: GLOBOCAN estimates of incidence and mortality worldwide for 36 cancers in 185 countries. CA Cancer J. Clin. 2021. [CrossRef] [PubMed] 
27. Siegel, R.L.; Miller, K.D.; Jemal, A. Cancer statistics, 2020. CA Cancer J. Clin. 2020, 70, 7-30. [CrossRef]

28. World Health Organization. Breast Cancer-WHOI World Health Organization. Available online: https://www.who.int/newsroom/fact-sheets/detail/breast-cancer (accessed on 1 May 2021).

29. Fragomeni, S.M.; Sciallis, A.; Jeruss, J.S. Molecular Subtypes and Local-Regional Control of Breast Cancer. Surg. Oncol. Clin. N. Am. 2018, 27, 95-120. [CrossRef]

30. Goldhirsch, A.; Winer, E.P.; Coates, A.S.; Gelber, R.D.; Piccart-Gebhart, M.; Thürlimann, B.; Senn, H.J. Personalizing the treatment of women with early breast cancer: Highlights of the St Gallen International Expert Consensus on the primary therapy of early breast cancer 2013. Ann. Oncol. 2013, 24, 2206-2223. [CrossRef]

31. Yersal, O.; Barutca, S. Biological subtypes of breast cancer: Prognostic and therapeutic implications. World J. Clin. Oncol. 2014, 5, 412-424. [CrossRef]

32. Dai, J.; Jian, J.; Bosland, M.; Frenkel, K.; Bernhardt, G.; Huang, X. Roles of hormone replacement therapy and iron in proliferation of breast epithelial cells with different estrogen and progesterone receptor status. Breast 2008, 17, 172-179. [CrossRef] [PubMed]

33. Trendowski, M. Recent advances in the development of antineoplastic agents derived from natural products. Drugs 2015, 75, 1993-2016. [CrossRef] [PubMed]

34. Garrido-Castro, A.C.; Lin, N.U.; Polyak, K. Insights into molecular classifications of triple-negative breast cancer: Improving patient selection for treatment. Cancer Discov. 2019, 9, 176-198. [CrossRef]

35. Yin, L.; Duan, J.J.; Bian, X.W.; Yu, S.C. Triple-negative breast cancer molecular subtyping and treatment progress. Breast Cancer Res. 2020, 22, 61. [CrossRef] [PubMed]

36. Fisusi, F.A.; Akala, E.O. Drug combinations in breast cancer therapy. Pharm. Nanotechnol. 2019, 7, 3-23. [CrossRef] [PubMed]

37. Masui, K.; Gini, B.; Wykosky, J.; Zanca, C.; Mischel, P.S.; Furnari, F.B.; Cavenee, W.K. A tale of two approaches: Complementary mechanisms of cytotoxic and targeted therapy resistance may inform next-generation cancer treatments. Carcinogenesis 2013, 34, 725-738. [CrossRef]

38. Amable, L. Cisplatin resistance and opportunities for precision medicine. Pharmacol. Res. 2016, 106, 27-36. [CrossRef]

39. Pádua, D.; Rocha, E.; Gargiulo, D.; Ramos, A.A. Bioactive compounds from brown seaweeds: Phloroglucinol, fucoxanthin and fucoidan as promising therapeutic agents against breast cancer. PhytoChem. Lett. 2015, 14, 91-98. [CrossRef]

40. Yun, C.W.; Kim, H.J.; Lee, S.H. Therapeutic application of diverse marine-derived natural products in cancer therapy. Anticancer Res. 2019, 39, 5261-5284. [CrossRef]

41. Lopes-Costa, E.; Abreu, M.; Gargiulo, D.; Rocha, E.; Ramos, A.A. Anticancer effects of seaweed compounds fucoxanthin and phloroglucinol, alone and in combination with 5-fluorouracil in colon cells. J. Toxicol. Environ. Health A 2017, 80, 776-787. [CrossRef]

42. Almeida, T.P.; Ferreira, J.; Vettorazzi, A.; Azqueta, A.; Rocha, E.; Ramos, A.A. Cytotoxic activity of fucoxanthin, alone and in combination with the cancer drugs imatinib and doxorubicin, in CML cell lines. Environ. Toxicol. Pharmacol. 2018, 59, 24-33. [CrossRef]

43. Vijay, K.; Sowmya, P.R.; Arathi, B.P.; Shilpa, S.; Shwetha, H.J.; Raju, M.; Baskaran, V.; Lakshminarayana, R. Low-dose doxorubicin with carotenoids selectively alters redox status and upregulates oxidative stress-mediated apoptosis in breast cancer cells. Food Chem. Toxicol. 2018, 118, 675-690. [CrossRef]

44. Wang, Z.; Li, H.; Dong, M.; Zhu, P.; Cai, Y. The anticancer effects and mechanisms of fucoxanthin combined with other drugs. J. Cancer Res. Clin. Oncol. 2019, 145, 293-301. [CrossRef] [PubMed]

45. Cherry, P.; O’Hara, C.; Magee, P.J.; McSorley, E.M.; Allsopp, P.J. Risks and benefits of consuming edible seaweeds. Nutr. Rev. 2019, 77, 307-329. [CrossRef] [PubMed]

46. Kim, J.B.; Stein, R.; O'Hare, M.J. Three-dimensional in vitro tissue culture models of breast cancer-A review. Breast Cancer Res. Treat. 2004, 85, 281-291. [CrossRef]

47. Verjans, E.T.; Doijen, J.; Luyten, W.; Landuyt, B.; Schoofs, L. Three-dimensional cell culture models for anticancer drug screening: Worth the effort? J. Cell Physiol. 2018, 233, 2993-3003. [CrossRef] [PubMed]

48. Kapałczyńska, M.; Kolenda, T.; Przybyła, W.; Zajączkowska, M.; Teresiak, A.; Filas, V.; Ibbs, M.; Bliźniak, R.; Łuczewski, Ł.; Lamperska, K. 2D and 3D cell cultures-A comparison of different types of cancer cell cultures. Arch. Med. Sci. 2018, 14, 910-919. [CrossRef]

49. Santo, V.E.; Rebelo, S.P.; Estrada, M.F.; Alves, P.M.; Boghaert, E.; Brito, C. Drug screening in 3D in vitro tumor models: Overcoming current pitfalls of efficacy read-outs. Biotechnol. J. 2017, 12. [CrossRef] [PubMed]

50. Imamura, Y.; Mukohara, T.; Shimono, Y.; Funakoshi, Y.; Chayahara, N.; Toyoda, M.; Kiyota, N.; Takao, S.; Kono, S.; Nakatsura, T.; et al. Comparison of 2D- and 3D-culture models as drug-testing platforms in breast cancer. Oncol. Rep. 2015, 33, 1837-1843. [CrossRef] [PubMed]

51. Konishi, I.; Hosokawa, M.; Sashima, T.; Kobayashi, H.; Miyashita, K. Halocynthiaxanthin and fucoxanthinol isolated from Halocynthia roretzi induce apoptosis in human leukemia, breast and colon cancer cells. Comp. BioChem. Physiol. C Toxicol. Pharmacol. 2006, 142, 53-59. [CrossRef]

52. Yamamoto, K.; Ishikawa, C.; Katano, H.; Yasumoto, T.; Mori, N. Fucoxanthin and its deacetylated product, fucoxanthinol, induce apoptosis of primary effusion lymphomas. Cancer Lett. 2011, 300, 225-234. [CrossRef]

53. De la Mare, J.A.; Sterrenberg, J.N.; Sukhthankar, M.G.; Chiwakata, M.T.; Beukes, D.R.; Blatch, G.L.; Edkins, A.L. Assessment of potential anti-cancer stem cell activity of marine algal compounds using an in vitro mammosphere assay. Cancer Cell Int. 2013, 13, 39. [CrossRef] 
54. Møller, P. The alkaline comet assay: Towards validation in biomonitoring of DNA damaging exposures. Basic. Clin. Pharmacol. Toxicol. 2006, 98, 336-345. [CrossRef]

55. Leon-Galicia, I.; Diaz-Chavez, J.; Albino-Sanchez, M.E.; Garcia-Villa, E.; Bermudez-Cruz, R.; Garcia-Mena, J.; Herrera, L.A.; García-Carrancá, A.; Gariglio, P. Resveratrol decreases Rad51 expression and sensitizes cisplatin-resistant MCF-7 breast cancer cells. Oncol. Rep. 2018, 39, 3025-3033. [CrossRef]

56. Lee, K.S.; Lee, M.G.; Kwon, Y.S.; Nam, K.S. Arctigenin enhances the cytotoxic effect of doxorubicin in MDA-MB-231 breast cancer cells. Int. J. Mol. Sci. 2020, 21, 2997. [CrossRef]

57. Antberg, L.; Cifani, P.; Levander, F.; James, P. Pathway-centric analysis of the DNA damage response to chemotherapeutic agents in two breast cell lines. EuPA Open Proteom. 2015, 8, 128-136. [CrossRef]

58. Pilco-Ferreto, N.; Calaf, G.M. Influence of doxorubicin on apoptosis and oxidative stress in breast cancer cell lines. Int. J. Oncol. 2016, 49, 753-762. [CrossRef]

59. Yang, F.; Teves, S.S.; Kemp, C.J.; Henikoff, S. Doxorubicin, DNA torsion, and chromatin dynamics. Biochim. Biophys. Acta 2014, 1845, 84-89. [CrossRef]

60. Kim, H.S.; Lee, Y.S.; Kim, D.K. Doxorubicin exerts cytotoxic effects through cell cycle arrest and Fas-mediated cell death Pharmacology 2009, 84, 300-309. [CrossRef]

61. Lin, S.R.; Chang, C.H.; Hsu, C.F.; Tsai, M.J.; Cheng, H.; Leong, M.K.; Sung, P.J.; Chen, J.C.; Weng, C.F. Natural compounds as potential adjuvants to cancer therapy: Preclinical evidence. Br. J. Pharmacol. 2020, 177, 1409-1423. [CrossRef] [PubMed]

62. Liston, D.R.; Davis, M. Clinically relevant concentrations of anticancer drugs: A guide for nonclinical studies. Clin. Cancer Res. 2017, 23, 3489-3498. [CrossRef]

63. Menéndez-Menéndez, J.; Hermida-Prado, F.; Granda-Díaz, R.; González, A.; García-Pedrero, J.M.; Del-Río-Ibisate, N.; GonzálezGonzález, A.; Cos, S.; Alonso-González, C.; Martínez-Campa, C. Deciphering the molecular basis of melatonin protective effects on breast cells treated with doxorubicin: TWIST1 a transcription factor involved in EMT and metastasis, a novel target of melatonin. Cancers 2019, 11, 1011. [CrossRef]

64. Prabhakaran, P.; Hassiotou, F.; Blancafort, P.; Filgueira, L. Cisplatin induces differentiation of breast cancer cells. Front. Oncol. 2013, 3, 134. [CrossRef] [PubMed]

65. Hosokawa, M.; Kudo, M.; Maeda, H.; Kohno, H.; Tanaka, T.; Miyashita, K. Fucoxanthin induces apoptosis and enhances the antiproliferative effect of the PPARgamma ligand, troglitazone, on colon cancer cells. Biochim. Biophys. Acta 2004, 1675, 113-119. [CrossRef] [PubMed]

66. Wang, L.; Zeng, Y.; Liu, Y.; Hu, X.; Li, S.; Wang, Y.; Li, L.; Lei, Z.; Zhang, Z. Fucoxanthin induces growth arrest and apoptosis in human bladder cancer T24 cells by up-regulation of p21 and down-regulation of mortalin. Acta Biochim. Biophys. Sin. 2014, 46, 877-884. [CrossRef] [PubMed]

67. Wu, H.L.; Fu, X.Y.; Cao, W.Q.; Xiang, W.Z.; Hou, Y.J.; Ma, J.K.; Wang, Y.; Fan, C.D. Induction of apoptosis in human glioma cells by fucoxanthin via triggering of ROS-mediated oxidative damage and regulation of MAPKs and PI3K-AKT pathways. J. Agric. Food Chem. 2019, 67, 2212-2219. [CrossRef] [PubMed]

68. Shin, J.; Song, M.-H.; Oh, J.-W.; Keum, Y.-S.; Saini, R.K. Pro-oxidant actions of carotenoids in triggering apoptosis of cancer cells: A review of emerging evidence. Antioxidants 2020, 9, 532. [CrossRef]

69. Liu, C.L.; Chiu, Y.T.; Hu, M.L. Fucoxanthin enhances HO-1 and NQO1 expression in murine hepatic BNL CL.2 cells through activation of the Nrf2/ARE system partially by its pro-oxidant activity. J. Agric. Food Chem. 2011, 59, 11344-11351. [CrossRef]

70. Zurina, I.M.; Gorkun, A.A.; Dzhussoeva, E.V.; Kolokoltsova, T.D.; Markov, D.D.; Kosheleva, N.V.; Morozov, S.G.; Saburina, I.N. Human melanocyte-derived spheroids: A precise test system for drug screening and a multicellular unit for tissue engineering. Front. Bioeng. Biotechnol. 2020, 8, 540. [CrossRef]

71. Terasaki, M.; Maeda, H.; Miyashita, K.; Mutoh, M. Induction of anoikis in human colorectal cancer cells by fucoxanthinol. Nutr. Cancer 2017, 69, 1-10. [CrossRef]

72. Terasaki, M.; Matsumoto, N.; Hashimoto, R.; Endo, T.; Maeda, H.; Hamada, J.; Osada, K.; Miyashita, K.; Mutoh, M. Fucoxanthin administration delays occurrence of tumors in xenograft mice by colonospheres, with an anti-tumor predictor of glycine. J. Clin. BioChem. Nutr. 2019, 64, 52-58. [CrossRef]

73. Hongisto, V.; Jernström, S.; Fey, V.; Mpindi, J.P.; Kleivi Sahlberg, K.; Kallioniemi, O.; Perälä, M. High-throughput 3D screening reveals differences in drug sensitivities between culture models of JIMT1 breast cancer cells. PLoS ONE 2013, 8, e77232. [CrossRef] [PubMed]

74. Lovitt, C.J.; Shelper, T.B.; Avery, V.M. Doxorubicin resistance in breast cancer cells is mediated by extracellular matrix proteins. BMC Cancer 2018, 18, 41. [CrossRef]

75. Prabst, K.; Engelhardt, H.; Ringgeler, S.; Hubner, H. Basic. colorimetric proliferation assays: MTT, WST, and Resazurin. Methods Mol. Biol. 2017, 1601,1-17. [CrossRef]

76. Kumar, P.; Nagarajan, A.; Uchil, P.D. Analysis of cell viability by the lactate dehydrogenase assay. Cold Spring Harb. Protoc. 2018, 2018. [CrossRef]

77. Malhão, F.; Ramos, A.A.; Macedo, A.C.; Rocha, E. Cytotoxicity of seaweed compounds, alone or combined to reference drugs, against breast cell lines cultured in 2D and 3D. Toxics 2021, 9, 24. [CrossRef] [PubMed]

78. Huang, Z.; Yu, P.; Tang, J. Characterization of triple-negative breast cancer MDA-MB-231 cell spheroid model. Oncol. Targets Ther. 2020, 13, 5395-5405. [CrossRef] 
79. Fischer, U.; Schulze-Osthoff, K. Apoptosis-based therapies and drug targets. Cell Death Differ. 2005, 12, 942-961. [CrossRef]

80. Chen, D.L.; Engle, J.T.; Griffin, E.A.; Miller, J.P.; Chu, W.; Zhou, D.; Mach, R.H. Imaging caspase-3 activation as a marker of apoptosis-targeted treatment response in cancer. Mol. Imaging Biol. 2015, 17, 384-393. [CrossRef]

81. Muftah, A.A.; Aleskandarany, M.A.; Al-Kaabi, M.M.; Sonbul, S.N.; Diez-Rodriguez, M.; Nolan, C.C.; Caldas, C.; Ellis, I.O.; Rakha, E.A.; Green, A.R. Ki67 expression in invasive breast cancer: The use of tissue microarrays compared with whole tissue sections. Breast Cancer Res. Treat. 2017, 164, 341-348. [CrossRef]

82. Soliman, N.A.; Yussif, S.M. Ki-67 as a prognostic marker according to breast cancer molecular subtype. Cancer Biol. Med. 2016, 13, 496-504. [CrossRef] [PubMed]

83. Hershey, B.J.; Vazzana, R.; Joppi, D.L.; Havas, K.M. Lipid droplets define a sub-population of breast cancer stem cells. J. Clin. Med. 2019, 9, 87. [CrossRef]

84. Cheng, J.; Fujita, A.; Ohsaki, Y.; Suzuki, M.; Shinohara, Y.; Fujimoto, T. Quantitative electron microscopy shows uniform incorporation of triglycerides into existing lipid droplets. HistoChem. Cell Biol. 2009, 132, 281-291. [CrossRef] [PubMed]

85. Gammone, M.A.; D'Orazio, N. Anti-obesity activity of the marine carotenoid fucoxanthin. Mar. Drugs 2015, 13, 2196-2214. [CrossRef]

86. Shyu, P., Jr.; Wong, X.; Fah, A.; Crasta, K.; Thibault, G. Dropping in on lipid droplets: Insights into cellular stress and cancer. Biosci. Rep. 2018, 38. [CrossRef]

87. Bojko, A.; Staniak, K.; Czarnecka-Herok, J.; Sunderland, P.; Dudkowska, M.; Śliwińska, M.A.; Salmina, K.; Sikora, E. Improved autophagic flux in escapers from doxorubicin-induced senescence/polyploidy of breast cancer cells. Int. J. Mol. Sci. 2020, 21, 6084. [CrossRef] [PubMed]

88. Holliday, D.L.; Speirs, V. Choosing the right cell line for breast cancer research. Breast Cancer Res. 2011, 13, 215. [CrossRef] [PubMed]

89. Subik, K.; Lee, J.-F.; Baxter, L.; Strzepek, T.; Costello, D.; Crowley, P.; Xing, L.; Hung, M.-C.; Bonfiglio, T.; Hicks, D.G.; et al. The expression patterns of ER, PR, HER2, CK5/6, EGFR, Ki-67 and AR by immunohistochemical analysis in breast cancer cell lines. Breast Cancer 2010, 4, 35-41. [CrossRef]

90. Malhão, F.; Ramos, A.A.; Buttachon, S.; Dethoup, T.; Kijjoa, A.; Rocha, E. Cytotoxic and antiproliferative effects of preussin, a hydroxypyrrolidine derivative from the marine sponge-associated fungus Aspergillus candidus KUFA 0062, in a panel of breast cancer cell lines and using 2D and 3D cultures. Mar. Drugs 2019, 17, 448. [CrossRef] [PubMed]

91. Piccinini, F. AnaSP: A software suite for automatic image analysis of multicellular spheroids. Comput. Methods Programs Biomed. 2015, 119, 43-52. [CrossRef] [PubMed]

92. Sales Gil, R.; Vagnarelli, P. Ki-67: More hidden behind a 'classic proliferation marker'. Trends BioChem. Sci. 2018, 43, 747-748. [CrossRef]

93. Bressenot, A.; Marchal, S.; Bezdetnaya, L.; Garrier, J.; Guillemin, F.; Plenat, F. Assessment of apoptosis by immunohistochemistry to active caspase-3, active caspase-7, or cleaved PARP in monolayer cells and spheroid and subcutaneous xenografts of human carcinoma. J. HistoChem. CytoChem. 2009, 57, 289-300. [CrossRef] [PubMed]

94. Hammer, O.; Harper, D.; Ryan, P. PAST: Paleontological Statistics Software Package for education and data analysis. Palaeontol. Electron. 2001, 4, 1-9.

95. Gaetano, J. Holm-Bonferroni Sequential Correction: An Excel Calculator (v. 1.3) Microsoft Excel Workbook. Available online: https: //www.researchgate.net/publication/322569220_Holm-Bonferroni_sequential_correction_An_Excel_calculator_13 (accessed on 1 June 2021).

96. Holm, S. A simple sequentially rejective multiple test procedure. Scand. Stat. Theory Appl. 1979, 6, 65-70. 